\title{
LA (IN)CONSTITUCIONALIDAD DE LAS RESTRICCIONES Y SUSPENSIÓN DE LA LIBERTAD DE CIRCULACIÓN POR EL CONFINAMIENTO FRENTE A LA COVID
}

\author{
Lorenzo Cotino Hueso \\ Catedrático de Derecho Constitucional, \\ Universitat de Valéncia
}

Cómo citar este artículo / Citation: Cotino Hueso, L. (2021). La (in)constitucionalidad

de las restricciones y suspensión de la libertad de circulación

por el confinamiento frente a la covid. Garrido López, C. (coord.)

Excepcionalidad y Derecho: el estado de alarma en España,

Colección Obras colectivas, Fundación Manuel Giménez Abad, Zaragoza.

DOI: https://doi.org/10.47919/FMGA.OC21.0004

SUMARIO: I. A MODO DE INTRODUCCIÓN, A VUELTAS SOBRE UN

PUZLE CONSTITUCIONAL QUE NO ACABA DE ENCAJAR. II. RESTRICCIONES DE LA LIBERTAD DE CIRCULACIÓN EN LA LUCHA CONTRA LA COVID PARA LA PROTECCIÓN DE VIDA, INTEGRIDAD Y SALUD PÚBLICA: 1. Restricciones en el Reglamento sanitario internacional y los confinamientos. 2. La vida, integridad y salud pública predominan, pero no jerárquicamente, sobre los derechos restringidos. III. EL CONFINAMIENTO ESTRICTO AFECTÓ A LA LIBERTAD PERSONAL. IV. LA LIBERTAD DE CIRCULACIÓN, LA GRAN AFECTADA POR LAS RESTRICCIONES: 1. EI contenido constitucional de la libertad de circulación. 2. Ordenación y delimitación de la libertad de circulación. La LOAES no es parámetro de su restricción o suspensión. V. EL CONFINAMIENTO ESTRICTO A TRAVÉS DE DECRETO 463/2020 DE ALARMA QUE SUSPENDIÓ LA LIBERTAD DE CIRCULACIÓN: 1. Sí, se suspendió la libertad de circulación con el primer Decreto de alarma. 2. La "mayoría" considera que no hubo suspensión de la libertad de circulación. 3. Y el más difícil todavía: sí que hubo suspensión de derechos, pero para ello basta con la legislación de salud. VI. ESTADO DE EXCEPCIÓN Y DUDOSA ALTERACIÓN DEL ORDEN PÚBLICO: 1. Una "mayoría" considera que no se dio el presupuesto del estado de excepción. 2. 
Y otra "mayoría" entiende que sí que procedía el estado de excepción. VII. OTRA POSIBLE VÍA DE SOLUCIÓN APORTADA POR ESCOBAR A UNA SITUACIÓN LABERÍNTICA. VIII. PARA CONCLUIR: LA INEXISTENCIA DE UN BLOQUE DE CONSTITUCIONALIDAD Y LA POSIBLE DECISIÓN DEL TRIBUNAL CONSTITUCIONAL.

\section{A MODO DE INTRODUCCIÓN, A VUELTAS SOBRE UN PUZLE CONSTITUCIONAL QUE NO ACABA DE ENCAJAR}

El presente estudio se centra en las restricciones de la libertad de circulación en la lucha contra la covid. El análisis puede ser de interés respecto elementos básicos constitucionales y de la lucha contra la pandemia. En particular se vuelve sobre un debate del cual, además de una gran discusión entre juristas, están pendientes dos recursos de inconstitucionalidad. Se trata de un debate constitucional nacional puesto que la heterogeneidad en la materia es lo propio en Derecho comparado de la $\mathrm{UE}^{1}$, si bien como se apunta al final, la solución ha de venir inspirada por una visión internacional. En otros próximos trabajos me centro en los graves problemas de los límites de derechos a través de la legislación de salud ordinaria y la tensión apreciable entre constitucionalistas y muchos administrativistas ${ }^{2}$. O en las problemáticas constitucionales de las prohibiciones de pequeñas agrupaciones de personas, cierre de actividades $y$, sobre todo, las restricciones de la libertad de circulación condicionadas a la vacunación.

En el presente trabajo se analiza en particular el confinamiento estricto declarado en marzo de 2020. Se considera que el mismo afectó a la libertad personal, lo cual complica más si cabe su tratamiento constitucional. En

\footnotetext{
${ }^{1}$ Sobre las heterogéneas respuestas en la UE, por todos, hay que seguir DÍAZ CREGO, M. y KOTANDIS, S., States of emergency in response to the coronavirus crisis, Parlamento europeo, European Parliamentary Research Service, diciembre, 2020. Disponible en: https://www.europarl.europa.eu/RegData/etudes/BRIE/2020/649408/EPRS_BRI(2020)649408_ EN.pdf

${ }^{2}$ Sobre el tema me remito a próxima publicación centrada en el (mal) uso de la legislación de salud. Así como brevemente a "La segunda ola de fuertes restricciones a Nuestros Derechos sin la vacuna de las Garantías", Valencia Plaza, 1 de octubre de 2020. Disponible en: https://valenciaplaza.com/la-segunda-ola-de-fuertes-restricciones-a-nuestros-derechos-sin-lavacuna-de-suficientes-garantias

Asimismo, al debate con G. DOMÉNECH, en el Seminario "Una visión constitucionalista frente una visión administrativista respecto de las restricciones de derechos para la gestión de la pandemia de COVID-19", 26 de noviembre de 2020. Disponible en: https://www.youtube.com/watch?v=AJejAx8TsdM\&t=1s
} 
cualquier caso, la libertad de circulación fue sin duda la gran afectada entre las variadas limitaciones de derechos que se dieron. Se aborda para ello el contenido constitucional de la libertad de circulación. Especialmente se tiene en cuenta la particular naturaleza de este derecho por cuanto a de sus restricciones y de su ordenación y delimitación. Se sostiene que el artículo 20 Ley Orgánica 4/1981, de 1 de junio (LOAES) no determina cuándo la libertad de circulación está suspendida.

Pues bien, se (vuelve) a sostener que el confinamiento estricto a través de Decreto 463/2020 de alarma sí que suspendió la libertad de circulación. La hizo irreconocible afectando a su contenido esencial en los términos de la STC 11/1981, algo que sólo puede operarse bajo suspensión del derecho. No obstante, se recogen los legítimos argumentos de una "mayoría" que considera que no hubo suspensión de la libertad de circulación. Incluso de excelentes juristas que afirman que sí que hubo suspensión de derechos, pero para ello basta con la legislación de salud. De igual modo, se centra el análisis en si era obligatorio o posible adoptar el estado de excepción que sí que permite la suspensión de la libertad de circulación. Para ello, el artículo 13 LOAES exige como presupuesto una alteración del orden público que ciertamente fue dudosa. Pues bien, con cierta ironía se afirma cómo una "mayoría" considera que no se dio el presupuesto del estado de excepción. Mientras otra "mayoría" entiende que sí que hubo suspensión y procedía el estado de excepción. Se sostiene, con todas las dudas que habrá de resolver el TC, que no era inconstitucional la adopción del estado de excepción, incluso era lo más adecuado. Ello sin perjuicio de considerar legítimo el estado de alarma en razón del contexto fáctico en el que se dio y la falta de precedentes. Lejos de aportar más claridad el estudio finalmente abre una vía a partir de la propuesta de Escobar: redefinir el concepto de suspensión de derechos y relativizar la importancia de las garantías formales para centrarse de pleno en las garantías materiales de legalidad, necesidad, razonabilidad o proporcionalidad.

Finalmente, como otro elemento más de este puzle constitucional, que no acaba de encajar, se mantiene la tesis de que la LOAES por sí sola no es parámetro de la constitucionalidad de las medidas adoptadas. La compleja relación de los artículos 55 y 116 CE con la LOAES habrá de ser aclarada por el TC. Aquí se sostiene que no puede hablarse de un bloque de constitucionalidad, que sustenta en parte los recursos de constitucionalidad. En su caso, la violación de la LOAES puede implicar vulneraciones concretas de la 
Constitución, materiales o competenciales. Se cierra el estudio, no sin cierta frivolidad, pronosticando algunos elementos clave de la futura sentencia del TC que resuelva los mencionados recursos contra los Decretos de alarma.

Pese a que se sostenga la inconstitucionalidad del Decreto de alarma adoptado, vuelvo a reiterarme en las razones o posibles justificaciones, más políticas que constitucionales, para la adopción del Decreto de alarma. El mismo fue una respuesta ágil y rápida sin contar con precedentes, justificada e idónea para la finalidad, proporcional (pese a que afectaba al contenido esencial de la libertad de circulación y, por tanto, lo suspendía); una respuesta a una alerta sanitaria guiada por la propia LOAES (art. 4.1 b), además de legitimada políticamente (al menos al inicio) ${ }^{3}$.

\section{RESTRICCIONES DE LA LIBERTAD DE CIRCULACIÓN EN LA LUCHA CONTRA LA COVID PARA LA PROTECCIÓN DE VIDA, INTEGRIDAD Y SALUD PÚBLICA}

\section{Restricciones en el Reglamento sanitario internacional y los confinamientos}

El Reglamento Sanitario Internacional (2005) de la Organización Mundial de la Salud $^{4}$ recoge diversas recomendaciones de medidas a adoptar frente a epidemias. Así: "examinar los itinerarios realizados por zonas afectadas; someter a las personas sospechosas a observación de salud pública [vigilancia]; someter a cuarentena o aplicar otras medidas sanitarias para las personas sospechosas; denegar la entrada a las personas sospechosas o afectadas; denegar la entrada en las zonas afectadas a las personas no afectadas" (art. 18. $1^{\circ}$ ). Respecto de mercancías y medios de transporte se incluyen inspecciones, pruebas, medidas sanitarias, aislamiento o denegar la

\footnotetext{
3 Así, véase el apartado "A modo de justificación de una decisión posiblemente inconstitucional", en COTINO HUESO, L., "Confinamientos, libertad de circulación y personal, prohibición de reuniones y actividades y otras restricciones de derechos por la pandemia del coronavirus", Diario La Ley, núm. 9606, Sección Doctrina, 2 de Abril de 2020, Wolters Kluwer. Disponible en:

https://diariolaley.laleynext.es/Content/Documento.aspx?params=H4sIAAAAAAAEAMtMSbF1C TEAAmMDcwtjM7Wy1KLizPw8WyMDI6CYsYFaXn5KaoiLs21pXkpqWmZeagpISWZapUtckhlQaptWmJOcapaalJ-fjaKSfEwEwBQINdEYwAAAA==WKE

${ }^{4}$ OMS, Reglamento Sanitario Internacional (2005), Organización Mundial de la Salud, resolución WHA58.3 de la Asamblea Mundial de la Salud (3ª edición). 2016. Disponible en: https://www.who.int/ihr/publications/9789241580496/es/
} 
salida o entrada (art. 18. $2^{\circ}$ ). Entre las medidas de salud pública se permite que los Estados puedan exigir a los viajeros información sobre su destino, itinerario, sobre otros posibles contactos, examen de los documentos y también se contemplan exámenes médicos e inspección de equipajes (Título V, arts. 23 y ss.). También se regulan los supuestos en los que es posible exigir "un examen médico, la vacunación u otras medidas profilácticas, o certificado de vacunación o prueba de la aplicación de otras medidas profilácticas" (art. $31.1^{\circ}$ ) si hay riesgo o en razón del artículo 23 antes señalado. En el caso de negarse a dichas medidas, puede denegarse la entrada (art. $31.2^{\circ}$ ). Además, en todo caso es posible adoptar "Medidas sanitarias adicionales" (art. 43) intentando ser lo menos invasivas posibles basadas en principios científicos. Si conllevan "trabas significativas" para el tráfico internacional" deben comunicarse a la OMS, que en su caso puede pedir que se reconsideren (art. 43.4º). Asimismo se pide una evaluación de las medidas así adoptadas en tres meses (art. 43.6ำ. Otro Estado puede pedir aclaraciones de los motivos científicos y de salud pública (art. $43.7^{\circ}$ ).

Entre las muchas medidas en la lucha contra la covid, las centrales afectan a la libertad de circulación en sus más variados contenidos y facultades.

El confinamiento no es un concepto claramente delimitado. "Confinar" para la RAE implica "señalar a alguien una residencia obligatoria", "recluir algo o a alguien dentro de límites", "se obliga [...] a vivir temporalmente, en libertad, en un lugar distinto al de su domicilio." Se trata de la medida que se ha generalizado en diversos momentos de la lucha contra la pandemia en España así como en el resto del mundo ${ }^{5}$, si bien con no pocas variedades, intensidades, especialidades y excepciones.

Se ha denominado generalmente confinamiento estricto al que implica una prohibición general de salir del domicilio, o más bien de ocupación de vías y espacios públicos. De modo más estricto cuando la obligación general de permanecer en el domicilio va acompañada de un cese de las actividades no esenciales, así como la no asistencia presencial a los centros educativos y universidades.

En cualquier caso, cabe señalar que la propia OMS ha señalado que el confinamiento no debe ser la principal defensa o medio de control, sino que 5 Puede hacerse un seguimiento de la respuesta en diversos países en
https://en.wikipedia.org/wiki/COVID-19_lockdowns 
esencialmente deben utilizarse para reorganizar, reagrupar, reequilibrar sus recursos; proteger a los trabajadores de la salud que están agotados ${ }^{6}$. Las alternativas pasan obviamente por las mascarillas, las pruebas, los rastreos de contactos y el aislamiento, la respuesta sanitaria y la mejor información y convicción a la población.

El "confinamiento" no es una medida regulada tal cual en la normativa estatal, sólo de modo excepcional queda expresada en alguna normativa autonómica. Así, por ejemplo, la Ley de Gestión de Emergencias vasca (Decreto Legislativo 1/2017, de 27 de abril ) incluye entre las medidas del artículo 8. $1^{\circ}$ las de "confinamiento". También textualmente en el artículo 9 Ley 4/1997, de 20 de mayo, de Protección Civil de Cataluña.

El "toque de queda" es una clásica expresión, si bien sin carta de naturaleza jurídica por cuanto no está recogida en nuestro ordenamiento. El toque de queda implica la restricción horaria de la libertad de circulación de las personas, siendo por lo general nocturno.

Las restricciones territoriales de la libertad de circulación o confinamientos perimetrales incluyen variadas limitaciones a la movilidad entre zonas: áreas de salud, poblaciones, provincias y regiones, así como relativas a la circulación en las fronteras del Estado.

\section{La vida, integridad y salud pública predominan, pero no jerárquicamente, sobre los derechos restringidos}

Las restricciones a la libertad de circulación -y otros derechos- como medidas frente para la contención de la covid se adoptan esencialmente para la protección de la vida, la integridad y la salud pública. "Salus publica suprema lex est" o en palabras también de Bombillar parafraseando a Clinton "es la salud, estúpidos"7.

\footnotetext{
6 NAVARRO, D. (OMS), Reflections about the middle path, 2020. Disponible en: https://www.4sd.info/COVID-19-narratives/reflections-about-the-middle-path/ También, https://www.who.int/news-room/q-a-detail/herd-immunity-lockdowns-and-COVID-19

7 BOMBILLAR SÁEN, F. M., "Salus publica suprema lex est: intervención administrativa y gestión de la crisis del COVID-19", en RODRÍGUEZ AYUSO, J. F. y ATIENZA MACÍAS, E. (Coords.), Las respuestas del Derecho a las crisis de salud pública, Dykinson, 2020, pp. 61-77, concretamente, p. 77. Ver SARRIÓN ESTEVE, J., "The health, stupid. Thoughts on Spain in state of alarm and the limitation of fundamental rights" (30 de marzo de 2020), en takingalook, Disponible en: https://takingalook.ideasoneurope.eu/2020/03/30/the-health-stupid-thoughts-onspain-in-state-of-alarm-and-the-limitation-of-fundamental-rights/
} 
La salud pública es un bien constitucional conexo a la protección de la vida e integridad. En razón de la dimensión positiva u objetiva de estos derechos hay un mandato constitucional a todos poderes públicos de proteger la vida y la integridad (STC 53/985, de 18 de mayo, FFJJ 4ํy 5). Este deber de protección debe integrarse en cada decisión de todos los poderes públicos que deba articular los diversos derechos y bienes en juego. El ATC 40/2020, de 30 de abril (primera y hasta el momento única resolución del TC sobre restricciones por pandemia $)^{8}$ señala que dado el escaso conocimiento de la enfermedad y la "incertidumbre tan acentuada", "las medidas de distanciamiento social, confinamiento domiciliario y limitación extrema de los contactos y actividades grupales, son las únicas que se han adverado eficaces" para proteger la vida y la salud ( $\left.\mathrm{FJ} 4^{\circ}\right)$. Entre sus afirmaciones en esta dirección, se señala que "la justificación de la declaración del Estado de alarma buscan limitar el impacto que en la salud de los seres humanos, en su integridad física y en su derecho a la vida pueda tener la propagación del covid-19".

Peñalver ${ }^{9}$ ha criticado que el TC y el TS sigan un principio general casi absoluto de prevalencia de los derechos a la vida y a la salud ante la libertad de circulación (ATC 40/2020, FJ 4, así como TS de 19 de mayo de 2020, sección 4aㅡ , recurso ordinario núm. 99/2020, FJ 5). Ello se hace más manifiesto, y ciertamente más incorrecto, en la resolución del Defensor del Pueblo de 3 de septiembre de 2020, que justifica el confinamiento general sobre la base de una "jerarquía de Derechos" en virtud de la que la libertad de circulación está subordinada a los derechos a la vida ya la salud (FJ 10) ${ }^{10}$. Peñalver afirma que sería una inexistente y absoluta prevalencia constitucional, eludiendo los principios de necesidad, adecuación y proporcionalidad ${ }^{11}$. Ciertamente es

\footnotetext{
${ }^{8}$ Sobre la resolución y el derecho de reunión dedico mi estudio, "Las restricciones del derecho de reunión y manifestación bajo el Covid 19 (y la aparente constitucionalidad del decreto de alarma 463/2020 para el Tribunal Constitucional)", en RODRÍGUEZ AYUSO, J. F., y ATIENZA MACÍAS, E. (Eds.), Retos jurídico-éticos ante la crisis del Covid-19: perspectiva interdisciplinar, Wolters Kluwer, Madrid, 2020.

9 PEÑALVER Y CABRÉ, A., "Afectaciones a la libertad de circulación por la pandemia de la COVID-19 y su régimen sancionador en el estado de alarma", Revista Catalana de Derecho Público, núm. especial COVID-19, 2020.

10 "La primacía [...] una jerarquía de derechos, reclamaban decisiones de alcance general, indiferenciado, que hiciesen explícita esa jerarquía de derechos para el conjunto de la población. El estado de alarma fue el instrumento para hacer explícita la primacía del respeto a la vida y la salud.

[...] no haberlas tomado - mediante el estado de alarma u otras técnicas legislativas sin estado de alarma- hubiera sido, por omisión, subordinar la vida y la salud al pleno ejercicio de otros derechos fundamentales: esto sí hubiera sido, a juicio de esta institución, de mas que dudosa constitucionalidad."

${ }^{11}$ Ibídem.
} 
desafortunada dogmáticamente la afirmación general de una prevalencia o jerarquía general de derechos. Todo se hace depender de la puesta efectiva en peligro, la necesidad y la proporcionalidad de la concreta restricción que se adopte.

El Derecho debe armonizar y maximizar la eficacia de los derechos y bienes constitucionales. Sin acudir a una jerarquía, lo que está claro es que la preservación de la vida y la salud pública son finalidades esenciales en las decisiones que adopten los poderes públicos en sus ámbitos propios. Bilbao afirma que "El estado de alarma se declaró precisamente para hacer explícita esa primacía"12. Y también en sentido positivo, pues no le falta razón al Defensor del Pueblo cuando afirma que la inacción sí que hubiera supuesto la lesión de estos derechos ${ }^{13}$.

Y en la línea señalada por Doménech ${ }^{14}$ la preservación de la vida y la salud debe guiar la interpretación de las normas existentes incluso para colmar sus evidentes carencias, como sucede con la legislación de salud y, en especial, la Ley Orgánica 3/1986, de 14 de abril, de Medidas Especiales en Materia de Salud Pública (LOMESP). No sólo debe prevalecer el principio de interpretación restrictiva de los límites, sino el de la vida y la salud.

A mi juicio más que jerarquización de derechos -que no se puede admitir dogmáticamente- ha habido casi un peligroso automatismo. Se ha dado una presunción general de peligro ${ }^{15}$ que ha llevado a eludir el análisis concreto de la necesidad y justificación objetiva de la medida. Y, al mismo tiempo, por lo general no se ha valorado la existencia de peligro más concreta (que exige el juicio de necesidad) y, sobre todo, estudiar alternativas menos graves exigidas por la alternatividad-proporcionalidad. Por lo general los (escasos) autos judiciales que no han admitido algunos excesos de las medidas autonómicas restrictivas sobre la base de la Ley Orgánica 3/1986 han intentado vencer esta

${ }^{12}$ BILBAO UBILLOS, J. M., "La libertad de reunión y manifestación en tiempos de pandemia", en BIGLINO CAMPOS, P, y DURÁN ALCA, J. F. (Dirs.), Los Efectos Horizontales de la COVID sobre el sistema constitucional, Fundación Manuel Giménez Abad, Zaragoza, 2020, p. 4.

${ }^{13}$ Resolución del Defensor del Pueblo de 3 de septiembre de 2020 de no interponer recurso de inconstitucionalidad. Disponible en: https://www.defensordelpueblo.es/wpcontent/uploads/2020/09/resolucion_estado_alarma.pdf

14 DOMENECH, G., "Comunidades autónomas, derechos fundamentales y COVID-19", Almacén de Derecho, 21 de julio 2020. Disponible en: https://almacendederecho.org/comunidades-autonomas-derechos-fundamentales-y-COVID-19

${ }^{15}$ DE MIGUEL BERIAIN, I. y RUEDA, J., "Immunity passports, fundamental rights and public health hazards: a reply to Brown et al.", en J Med Ethics octubre, 2020 Vol 46 No 10, pp. 660661. 
inercia $^{16}$. Ello estaba en su caso más justificado al inicio de la pandemia con una incertidumbre enorme por el que se ha restringido especialmente la libertad de circulación sin una valoración concreta de alternativas menos graves. Como afirmó el ATC 40/2020 "Ante esta incertidumbre tan acentuada y difícil de calibrar desde parámetros jurídicos que acostumbran a basarse en la seguridad jurídica que recoge el art. 9.3 de la Constitución, las medidas de distanciamiento social, confinamiento domiciliario y limitación extrema de los contactos y actividades grupales, son las únicas que se han adverado eficaces para limitar los efectos de una pandemia de dimensiones desconocidas hasta la fecha." (n०3).

\section{III.EL CONFINAMIENTO ESTRICTO AFECTÓ A LA LIBERTAD PERSONAL}

Según su intensidad y tipología, los confinamientos pueden ser también restricciones de la libertad personal del artículo $17 \mathrm{CE}$. La libertad personal que reconoce nuestro artículo $17 \mathrm{CE}$ es una garantía frente a las privaciones de libertad y detenciones. Y cabe recordar que alcanza asimismo garantías frente a las "retenciones" por las FCS -p.e. pruebas de alcoholemia SSTC 107/1985, de 7 de octubre y 22/1988, de 18 de febrero- e incluso a las diligencias de identificación con acompañamiento obligatorio a dependencias policiales (STC 341/1993, FJ $4^{\circ}$ ). Se afecta al artículo 17 CE pues es "una situación que va más allá de una mera inmovilización de la persona, instrumental de prevención o de indagación, y por ello ha de ser considerada como una modalidad de privación de libertad" (id.).

No es fácil distinguir la libertad deambulatoria propia de la libertad personal y la libertad de circulación. Ceballos ${ }^{17}$ afirma que la libertad personal protege frente a decisiones que no permiten deambular, "ir y venir", que obligan a "permanecer inmóvil" y no "abandonar el lugar en que se encuentra". Recuerda que la Constitución francesa de 1791 garantizaba "libertad de cada hombre de ir, permanecer, partir, sin poder ser arrestado o detenido" (d'aller, de rester, de partir, sans pouvoir être arrêté, ni détenu). En esta línea, para Díez-Picazo, la libertad protegida por el artículo $17 \mathrm{CE}$ es "la libertad deambulatoria en cuanto

\footnotetext{
${ }^{16}$ Especialmente los TSJ más recelosos han sido los de Aragón y País Vasco. De este, en la línea expuesta, puede seguirse el Auto 32/2020 de 22 de octubre de 2020, TSJ País Vasco.

17 CEBALlOS BEDOYA, J. S., “¿Cuándo una medida es "privativa de la libertad"?". Nuevo Foro Penal, núm. 80, 2013, pp. 94-116.
} 
tal, no a los lugares donde uno puede moverse"18. Bastida vinculó la libertad personal con la deambulatoria ${ }^{19}$. Para Durán $\mathrm{Alba}^{20}$ estas dos libertades en todo caso "tienen un carácter manifiestamente autónomo, [...] aunque la libertad de circulación pueda entenderse como concreción de la libertad personal".

La libertad personal ampara frente "cualquier otra forma de limitación de la autonomía de la persona" (Corte Constitucional Colombia Sentencia C-024 de 1994). Ceballos considera que la libertad personal incluso confiere "la posibilidad individual de relacionarse o no con el entorno y con los demás; de ejercer o no ejercer sus demás derechos y libertades." En esta dirección la STEDH Guzzardi $v$ Italia de 6 de noviembre de 1980 consideró que había sido privado de libertad al confinado en un $5 \%$ del territorio insular, y sin barreras físicas de una isla de $51 \mathrm{Km}$, esto es, podía moverse por una superficie similar a la del Principado de Mónaco. La STEDH Nielsen $v$ Dinamarca, de 28 de noviembre de 1988 no consideró privación de libertad el internamiento de un niño en un psiquiátrico por decisión de su madre porque estaba en condiciones de establecer relaciones en circunstancias similares a las de un niño. La STC 178/1985 consideró proporcional que el quebrado sí podía ser sometido a un arresto domiciliario, medida que le dejaba intactas al menos algunas de las posibilidades de relacionarse con los suyos. Así las cosas, Ceballos concluye ${ }^{21}$ que una medida es privativa de la libertad cuando implica obstaculizar, con medios tan severos como el arresto o la detención, las posibilidades individuales de entablar relaciones con el entorno y con los demás, o de no hacerlo.

Durán ha señalado que la libertad de circulación es "emanación de la libertad personal" 22 . En esta dirección afirma que el confinamiento domiciliario o en otro establecimiento -sanitario, hotel, etc.- "parecen encajar más bien en una restricción de la libertad personal amparada en el art. 17 CE".

Pues bien, por lo que ahora interesa el confinamiento más estricto como el de la primera ola en primavera de 2020 sí que puede considerarse una limitación de la libertad personal del artículo 17 CE. También González de Lara recuerda

\footnotetext{
${ }^{18}$ DÍEZ PICAZO, L. M., Sistema de derechos Fundamentales, Madrid, Thomson Civitas, p. 232.

19 BASTIDA FREIJEDO, F., "Libertad de circulación", en ARAGÓN REYES, M. (Coord.) Temas básicos de Derecho Constitucional, Tomo III, Civitas, Madrid, 2001, pp. 153-155.

${ }^{20}$ DURÁN ALBA, J. F., "Afectaciones a la libertad de circulación... cit.

21 CEBALLOS BEDOYA, J. S., op. cit. p. 144.

${ }^{22}$ DURÁN ALVA, J. F., "Afectaciones a la libertad de circulación... op. cit. p. 3 ver también p. 8.
} 
que la situación impuesta "está cercana al arresto domiciliario" ${ }^{23}$. Como ha señalado Sieira, "la medida del confinamiento es la más intensa restricción de la libertad personal que, en general, la gran mayoría de los ciudadanos no privados de libertad en virtud de actuaciones judiciales, han sufrido en sus vidas [...] Se ha obligado a permanecer en el domicilio, bajo la amenaza de sanciones penales y administrativas."

En consecuencia, una limitación de la libertad personal debe superar más intensas garantías de legalidad y control judicial y un más estricto canon de evaluación que las restricciones de la libertad de circulación. En esta dirección, la STC 169/2001, de 16 de julio, FJ 4,a) admitió una restricción de la libertad de circulación a extranjeros por tratarse de esta libertad, señalando que no se trataba de la libertad personal, que hubiera implicado un canon de control más estricto $^{24}$. En el recurso de inconstitucionalidad n. ${ }^{\circ}$ 2054-2020 al primer Decreto 463/2020, de 14 de marzo de alarma presentado por los diputados del Grupo Parlamentario Vox se considera que el confinamiento estricto del primer Decreto de alarma "constituye, por su rigidez e intensidad, una verdadera privación de libertad" ( $\left.n^{\circ} 33\right)^{25}$.

Abordar un confinamiento estricto bajo el artículo $17 \mathrm{CE}$ no hace sino dificultar su admisibilidad constitucional. El confinamiento sería una restricción de libertad personal que a través del Decreto de alarma puede considerarse que contaría con la previsión legal suficiente dado el valor de ley del Decreto de alarma. En todo caso, sería importante para el futuro que la regulación constitucional contemplara específicamente la posibilidad del confinamiento y, en especial, la ley de desarrollo del artículo 116 CE. Las carencias de la LOAES son aún mayores si se aprecia desde la libertad personal. Asimismo, se hace muy difícil pensar en el cumplimiento de todas las garantías judiciales correspondientes de un confinamiento masivo bajo decreto de alarma. Y desde la libertad personal cabe descartar totalmente un confinamiento estricto sobre

${ }^{23}$ GONZÁLEZ DE RALA MINGO, S., "Hacia la era de la "nueva anormalidad" jurídica instaurada por la vía del uso de los Reales Decretos y las Órdenes Ministeriales", Diario La Ley, núm. 9649, Sección Tribuna, 9 de Junio de 2020. Disponible en: https://diariolaley.laleynext.es/Content/DocumentoRelacionado.aspx?params=H4sIAAAAAAAE AMtMSbF1CTEAAmNDAyNDU7Wy1KLizPw827DM9NS8kIQA6jAwoSAAAAA=WKE

${ }_{24}^{24}[\mathrm{C}]$ on independencia de que si se llegara a la conclusión de que la medida impuesta afecta a la libre circulación de las personas, las exigencias de previsión legal y proporcionalidad debieran ser analizadas desde la perspectiva de un canon diferente al requerido por el derecho a la libertad personal."

${ }_{25}$ Disponible en: https://www.voxespana.es/wp-content/uploads/2020/04/recursoinconstitucionalidad-estado-alarma-VOX.pdf 
la base del artículo 3 Ley Orgánica 3/1986 dada su raquítica base legal, pues sólo podría adoptarse bajo la previsión de medidas "que se consideren necesarias en caso de riesgo de carácter transmisible".

\section{LA LIBERTAD DE CIRCULACIÓN, LA GRAN AFECTADA POR LAS RESTRICCIONES}

\section{El contenido constitucional de la libertad de circulación}

Con la libertad de circulación bien se cumple la famosa afirmación de que no sabemos lo que tenemos hasta que lo perdemos. No en vano se trata de una libertad "bastante discreta" entre otros derechos fundamentales de los que gozan de la máxima protección. El artículo $19 \mathrm{CE}$, sin perjuicio de su máximo reconocimiento internacional y constitucional, no ha contado con una intensa protección y ha tenido un muy escaso protagonismo hasta la fecha. En cierto modo su interés ha quedado absorbido por las libertades de circulación fundamentales de la UE de especial interés económico ${ }^{26}$. Asimismo, han tenido cierta relevancia los límites específicos de la libertad de circulación para los extranjeros. De ahí que, como recuerda Duran ${ }^{27}$, los pronunciamientos del TC sobre libertad de circulación no son especialmente escrupulosos, no existe una gran construcción del contenido del artículo $19 \mathrm{CE}$. Al tiempo, puede percibirse un carácter secundario de la libertad de circulación con relación a otros derechos. Como se ha adelantado con relación a la libertad personal del artículo 17 CE se da cierta relajación del principio de legalidad en el desarrollo, regulación y restricciones a este derecho.

El artículo 12 PIDCP garantiza la libertad de circulación ${ }^{28}$ y es de interés la Observación General oㅡ 27 sobre la misma ${ }^{29}$. Así, se parte de que "La libertad

${ }^{26}$ GONZÁLEZ-TREVIJANO, P. J., Libertades de circulación, residencia, entrada y salida en España Universidad Complutense de Madrid, 1991. Más centrados en el Derecho de la Unión, REIG FABADO, I. (Coord.), Libertad de circulación, asilo y refugio en la Unión Europea, Tirant lo Blanch, 2014 o ELVIRA PERALES, A., Libertad de circulación de personas en la Unión Europea: límites por razón de orden público, Centro de Estudios Políticos y Constitucionales (España), 2017.

${ }_{28}^{27}$ DURÁN ALBA, J. F., "Afectaciones a la libertad de circulación... op. cit.

28 Artículo 12: 1. Toda persona que se halle legalmente en el territorio de un Estado tendrá derecho a circular libremente por él y a escoger libremente en él su residencia. 2. Toda persona tendrá derecho a salir libremente de cualquier país, incluso del propio. 3. Los derechos antes mencionados no podrán ser objeto de restricciones salvo cuando estas se hallen previstas en la ley, sean necesarias para proteger la seguridad nacional, el orden público, la salud o la moral públicas o los derechos y libertades de terceros, y sean compatibles con los 
de circulación es una condición indispensable para el libre desarrollo de la persona. También está relacionada con otros derechos diversos consagrados en el Pacto" ( $\left.n^{\circ} 1\right)$. Sobre esta base se reconoce que "Toda persona que se encuentre legalmente dentro del territorio de un Estado disfruta, dentro de ese territorio, del derecho de desplazarse libremente y de escoger su lugar de residencia" ( $\left.n^{\circ} 4\right)$. Pese a que los límites estén previstos (incluido el motivo de la salud) "Las limitaciones permisibles que pueden imponerse a los derechos protegidos en virtud del artículo 12 no deben anular el principio de la libertad de circulación" ( $n^{\circ} 2$ ); "las restricciones no deben comprometer la esencia del derecho; no se debe invertir la relación entre derecho y restricción, entre norma y excepción. Las leyes que autoricen la aplicación de restricciones deben utilizar criterios precisos y no conferir una discrecionalidad sin trabas a los encargados de su aplicación". En este sentido, resulta de especial interés la importancia que se da a la seguridad jurídica y a la legalidad de las restricciones: "La propia ley tiene que determinar las condiciones en que pueden limitarse esos derechos." ( $\left.n^{\circ} 12\right)$. Además de la necesidad de las restricciones para una sociedad democrática, se exige la proporcionalidad, tanto de la ley ( $n^{\circ}$ 15) como de aplicación judicial y administrativa de las restricciones a la libertad de circulación ( $n^{\circ}$ 16).

EI TC ha expresado que "El art. 19 CE reconoce a 'los españoles' cuatro derechos fundamentales distintos: el derecho a elegir libremente su residencia, el derecho a circular por el territorio nacional, el derecho a entrar en España y el derecho a salir libremente del territorio nacional" (STC 72/2005, de 4 de abril, FJ 5, de nuevo en STC 146/2006, de 8 de mayo, FJ 2) ${ }^{30}$.

Figueroa afirma el principio iusfundamental de la libertad de circulación, en virtud del cual "Todos tienen la mayor libertad de circulación posible dentro de las posibilidades fácticas y jurídicas" ${ }^{31}$. A su juicio este principio no pierde validez (ni tampoco se suspende) porque de hecho no podamos circular. La

demás derechos reconocidos en el presente Pacto. 4. Nadie podrá ser arbitrariamente privado del derecho a entrar en su propio país.

${ }^{29}$ Comité de Derechos Humanos, Observación General 27 sobre Libertad de circulación (art. 12), de 02/11/99 (CCPR/C/21/Rev.1/Add.9, CCPR), Aprobado por el Comité en la 1783a sesión (67ํㅜ período de sesiones), celebrada el 18 de octubre de 1999. Disponible en: https://www.acnur.org/fileadmin/Documentos/BDL/2001/1400.pdf

${ }^{30}$ Lo recuerda DURÁN ALBA, J. F., "Afectaciones a la libertad de circulación derivadas del estado de alarma" en BIGLINO CAMPOS, P. y DURÁN ALBA, J. F., (Dirs.), Los efectos horizontales ... op. cit.

${ }^{31}$ GARCÍA FIGUEROA, A., "Estado de alarma, estado de excepción y libertad de circulación", 8 de abril 2020, en Almacén de Derecho. Disponible en: https://almacendederecho.org/estadode-alarma-estado-de-excepcion-y-libertad-de-circulacion 
libertad de circulación del artículo 19 CE implica esencialmente un límite "de los poderes públicos de no adoptar medidas que restrinjan $u$ obstaculicen ese derecho fundamental" (STC 8/1986, FJ $3^{\circ}$ ) y obviamente, si hay límites, que los mismos cumplan con los requisitos constitucionales.

Fernández De Gatta ${ }^{32}$ sintetiza al TC para afirmar que se trata de la "libertad de andar, transitar o deambular por todo el territorio nacional sin injerencia ni traba alguna", sin depender de un medio concreto para su ejercicio y sin que se supedite a un fin, causa o justificación concreta. (SsTC 59/1990, de 29 de marzo, 72/2005, de 4 de abril, y 18/2017, de 2 de febrero, entre otras). Como recuerda Peñalver ${ }^{33}$, la libertad de circulación es un medio necesario para hacer efectivos muchos otros derechos constitucionales que se pueden ver seriamente afectados sin la libertad de circulación, ya que requieren la movilidad para su satisfacción.

El artículo 19 CE completa su contenido constitucional con el mandato del artículo 139. $2^{\circ} \mathrm{CE}$ : "Ninguna autoridad podrá adoptar medidas que directa o indirectamente obstaculicen la libertad de circulación y establecimiento de las personas y la libre circulación de bienes en todo el territorio español." Como es sabido, se hace referencia a la libre circulación de bienes y personas por todo el territorio, "se trata del pilar esencial de la unidad de mercado, "supuestos irreductibles" de la "unicidad del orden económico nacional" (STC 64/1990, de 5 abril, con mención de las SSTC 96/1984 y 88/1986, sobre dos supuestos irreductibles, la libre circulación de bienes y personas por todo el territorio español, que ninguna autoridad podrá obstaculizar directa 0 indirectamente (art. 139.2 CE)". Ahora bien, esta dimensión económica, por importante que sea, no tiene una protección como derecho fundamental muy intensa. Así, este mandato constitucional no puede interpretarse estrictamente como que no son posibles los límites a estas libertades. En todo caso, dado el tenor literal de este precepto, las restricciones a la dimensión económica de la libertad de circulación habrán de ser muy restrictivamente interpretadas en lo que puedan afectar a la unidad económica.

\footnotetext{
${ }^{32}$ FERNÁNDEZ DE GATTA SÁNCHEZ, D., "Los problemas de las medidas jurídicas contra el coronavirus. Las dudas constitucionales sobre el estado de alarma y los excesos normativos", Diario La Ley, 9641. 2020. Disponible en: http://www.aepda.es/AEPDAEntrada-2808-Losproblemas-de-las-medidas-juridicas-contra-el-coronavirus-las-dudas-constitucionales-sobre-elEstado-de-Alarma-y-los-excesos-normativos.aspx

${ }^{33}$ PEÑALVER Y CABRÉ, A., "Afectaciones a la libertad de circulación ... op. cit.
} 


\section{Ordenación y delimitación de la libertad de circulación. La LOAES no es parámetro de su límite o suspensión}

Para analizar los límites en razón de la covid en la libertad de circulación procede una buena delimitación del derecho. No en vano algunas aparentes restricciones no serán tales ${ }^{34}$, sino una ordenación o delimitación de su contenido protegido ${ }^{35}$. Lo que no quede bajo el contenido normal de este derecho adecuadamente delimitado, no gozará de la protección iusfundamental. Ello será especialmente relevante cuando no se tenga un título para la circulación o deambulación por algunas zonas o espacios, especialmente privados, como pueda ser la propiedad o similares. No podrá hablarse en estos casos de límites o restricciones, sino de delimitación de la libertad de circulación.

En virtud de la libertad de circulación se deriva a mi juicio un "principio de preferente uso común" ${ }^{\prime 6}$ de los espacios y dominios públicos, que están de natural dispuestos para el ejercicio de la libertad de circulación (vías públicas, calles, carreteras, etc.). A partir de este principio de uso preferente, la ordenación general de la circulación y el tráfico no tiene por qué implicar un límite del derecho ${ }^{37}$. Asimismo, cuando se dan límites cabe tener en cuenta las alternativas para la movilidad, bien por limitación de número de ocupantes, por la existencia de otros medios de transporte, vías alternativas u horarios. Estas alternativas por cuanto sean reales, harán que las decisiones limitativas de uso de vías públicas ni siquiera deba considerarse una restricción de las libertades del artículo 19 CE o, como se señaló en la STC 28/1999, FJ 70 "sólo incidiría sobre esta última en un grado extraordinariamente limitado". En todo caso, sí que serán restricciones las prohibiciones totales o parciales a la libertad de

\footnotetext{
${ }^{34}$ Así, cabe partir de que "las libertades de circulación y residencia no confieren, como es natural, un poder jurídico omnímodo a favor de su titular, ya sea en orden a pasar por cualquier lugar, ya sea en orden a habitar en él" (STC 28/1999, FJ $7^{\circ}$ ).

${ }^{35}$ MARTÍN RETORTILLO, L. y DE OTTO PARDO, I., Derechos fundamentales y Constitución, Civitas, Madrid, 1988, entre otras, pp. 142, y 151 a 152; ver también recientemente, sobre esta dimensión subjetiva de los derechos fundamentales, MEDINA GUERRERO, M., La vinculación negativa del legislador a los derechos fundamentales, Mc Graw Hill, Madrid, 1996. SÁNCHEZ FERRIZ, R., Estudio sobre las libertades, (2 ${ }^{\mathrm{a}}$ ed.), Tirant lo Blanch, Valencia, 1995 pp. 44 a 48, 50 y 226.

${ }^{36}$ Art. 6 d) y arts. 85 y ss. Ley 33/2003, de 3 de noviembre, del Patrimonio de las Administraciones Públicas.

${ }^{37}$ No serían propiamente "limitaciones a la circulación", pese a que así las denomine el art. 38 Ley $37 / 2015$, de 29 de septiembre, de carreteras. Sobre el tema, sin perspectiva propiamente constitucional, MARTÍNEZ NIETO, A., "Coronavirus, tráfico y movilidad: Suspensión del derecho a la libre circulación por la alarma del COVID-19 y posibles lecciones del postcoronavirus para el futuro de movilidad", en Diario La Ley, ISSN 1989-6913, núm. 9613, 2020.
} 
circulación por seguridad ${ }^{38}$ o, como es el caso, por la pandemia. La libertad de circulación puede ser restringida por motivos de seguridad pública a través de órdenes y prohibiciones $^{39}$ y también en aplicación de la legislación de protección civil, que no ha sido aplicado en razón de la pandemia ${ }^{40}$.

La LOAES recoge expresamente algunas restricciones de la libertad de circulación. Así, el artículo 11 a) con relación al Decreto de alarma permite "Limitar la circulación o permanencia de personas o vehículos en horas y lugares determinados, o condicionarlas al cumplimiento de ciertos requisitos" ${ }^{41}$. El artículo 20 para el estado de alarma recoge las posibles restricciones "Cuando la autorización del Congreso comprenda la suspensión". Así, se dispone la "prohibición", así como acreditar la identidad indicando itinerario. Por "fundados motivos en razón a la peligrosidad que para el mantenimiento del orden público suponga la persona" $\left(20.7^{\circ}\right)$, es posible someter a comunicación previa dos días antes de todo desplazamiento $\left(20.3^{\circ}\right)$, que puede ser limitado (20. $\left.4^{\circ}\right)$. También se puede fijar la residencia a personas determinadas $\left(20.5^{\circ}\right)$.

Sobre esta base y como he sostenido, muchas de las medidas reguladas en el artículo 20 LOAES para el estado de excepción no implican necesariamente haber suspendido la libertad de circulación. Incluso bajo Derecho ordinario pueden darse límite y especialmente ordenaciones del ejercicio del derecho. Es más, algunas de estas medidas ni siquiera serán una restricción al derecho, sino una delimitación u ordenación del mismo. Así, es posible el establecimiento general de condiciones y requisitos a la circulación de

\footnotetext{
${ }^{38}$ Así, artículo 18 Real Decreto Legislativo 6/2015, de 30 de octubre, por el que se aprueba el texto refundido de la Ley sobre Tráfico, Circulación de Vehículos a Motor y Seguridad Vial. Así, entre otros, por motivos de "seguridad" se permite "la prohibición total o parcial de acceso a partes de la vía, bien con carácter general o para determinados vehículos, el cierre de determinadas vías". Ello está desarrollado en el artículo 39 Real Decreto 1428/2003, de 21 de noviembre, por el que se aprueba el Reglamento General de Circulación para la aplicación y desarrollo del texto articulado de la Ley sobre tráfico, circulación de vehículos a motor y seguridad vial, aprobado por el Real Decreto Legislativo 339/1990, de 2 de marzo. En situaciones de seguridad y excepcionalidad estas decisiones, de natural, contarán también con la cobertura de la normativa de seguridad o protección civil aplicable.

${ }^{39}$ Art. 14 Ley Orgánica 4/2015, habilitándose a restricciones por el tiempo imprescindible (art. 17. $1^{\circ}$ ) y que se puedan "establecer controles en las vías, lugares o establecimientos públicos" (art. 17.2으. Como medidas de seguridad extraordinarias del artículo 21. $1^{\circ}$ se habilita expresamente para "la prohibición del paso".

${ }^{40}$ El artículo 7 bis. 2ำ Ley $17 / 2015$ da cierta cobertura por cuanto las "órdenes e instrucciones" pueden afectar la libertad del artículo $19 \mathrm{CE}$, que bien pueden restringir la circulación, además bajo el deber de evitar la generación de riesgos (art. 7 ter $1^{\circ}$ ).

${ }^{41}$ Artículo 11 "el decreto de declaración del estado de alarma, o los sucesivos que durante su vigencia se dicten, podrán acordar las medidas siguientes: a) Limitar la circulación o permanencia de personas o vehículos en horas y lugares determinados, o condicionarlas al cumplimiento de ciertos requisitos".
} 
vehículos o personas, o caben prohibiciones para la circulación en lugares o vías privadas o incluso públicas, por cuanto no haya título que legitime la circulación. Asimismo, señalar el itinerario a seguir para llegar al lugar de destino entre las alternativas posibles, tampoco implica en la mayor parte de los supuestos ni siquiera una restricción del derecho. Por cuanto a la acreditación de la identidad, en su caso será un límite al ejercicio de la libre circulación que bien podrá contar con habilitación legal ordinaria y más en supuestos excepcionales.

Se trata de una cuestión relevante. No en vano, la adopción de algunas restricciones o meras ordenaciones que puedan incluirse en este artículo 20 LOAES podrían considerarse como suspensión del derecho y no tienen por qué serlo. Asimismo, se podría encorsetar excesivamente el tipo de medidas a adoptar a través del estado excepcional correspondiente. Es precisa una interpretación de la LOAES que resulte acorde a la necesaria eficacia del Derecho de excepción y supere las insuficiencias de la misma. Me remito en todo caso al apartado final VIII infra. Obviamente, la posición contraria es plenamente legítima ${ }^{42}$, si bien podría llevar a pensar que, por ejemplo, las limitaciones horarias o toque de queda no podría ser adoptado por un Decreto de alarma; o una mera prohibición de circular en un lugar, o la exigencia de identificación, entre otros. El TC habrá de dar luz a este respecto para el futuro.

\section{EL CONFINAMIENTO ESTRICTO A TRAVÉS DE DECRETO 463/2020 DE ALARMA QUE SUSPENDIÓ LA LIBERTAD DE CIRCULACIÓN}

El confinamiento estricto se dio especialmente en la primera ola con el Real Decreto 463/2020, de 14 de marzo, por el que se declara el estado de alarma para la gestión de la situación de crisis sanitaria ocasionada por la covid-19. Estuvo vigente los quince días iniciales y se prorrogó seis veces, hasta el 21 de junio. El artículo 7.1 impuso la prohibición general de "circular por las vías o espacios de uso público", permitiéndola sólo individualmente y bajo las

\footnotetext{
${ }^{42}$ Además de diversos autores que la sostienen, como infra (VIII) se recuerda, se trata de un elemento básico de la fundamentación de los dos recursos de inconstitucionalidad presentados contra los Decretos de alarma.
} 
excepciones previstas ${ }^{43}$. EI TC señaló la situación creada como "medida de confinamiento" (FJ $2^{\circ}$, ATC 40/2020, de 30 de abril).

Como asentó en especial la STC 83/2016, de 28 de abril, explican Garrido López $^{44}$ o Sieira Mucientes ${ }^{45}$ y en otro lugar hemos expuesto ${ }^{46}$, el Decreto de alarma tiene valor de ley y capacidad de desplazar las regulaciones ordinarias de la libertad de circulación y, al tiempo, capacidad de establecer restricciones directas y al ejercicio de esta libertad. Merced a habilitación normativa (D. Final $2^{2}$ Real Decreto 463/2020, de 14 de marzo) para el desarrollo y concreción se dio muy prolija y concreta normativa. Nunca la libertad de circulación estuvo tan regulada ${ }^{47}$.

Los ulteriores Decretos de alarma de otoño 2020, primero para Madrid ${ }^{48}$ y especialmente el más amplio Real Decreto 926/2020, de 25 de octubre ${ }^{49}$ establecieron restricciones de la libertad de circulación, especialmente confinamientos perimetrales de zonas, localidades, provincias y regiones, así

${ }^{43}$ Cabe recordar las excepciones: "a) Adquisición de alimentos, productos farmacéuticos y de primera Necesidad, así como adquisiciones y prestaciones de servicios especificados en el art. 10.

b) Asistencia a Centros, servicios y establecimientos sanitarios.

c) Desplazamiento al Lugar de trabajo para efectuar sume prestaciones laborales, profesional o empresarial.

d) Retorno al Lugar de residencia habitual.

e) Asistencia y cuidado a mayores, menores, Dependienta, personas con discapacidad o personas especialmente vulnerables.

f) Desplazamiento a Entidades Financieras y de seguros.

g) Por causa de fuerza mayor o situación de necesidad.

h) Cualquier otra actividad de análoga naturaleza".

${ }^{44}$ In toto, GARRIDO LÓPEZ, C., "Naturaleza jurídica y control jurisdiccional de las decisiones constitucionales de excepción", Revista Española de Derecho Constitucional, núm. 110. 2017.

45 SIEIRA MUCIENTES, S., "Los estados excepcionales", Revista de las Cortes Generales, 2018, núm. 104, pp. 361-393.

${ }^{46}$ COTINO HUESO, L., "Los derechos fundamentales en tiempos del Coronavirus. Régimen general y garantías y especial atención a las restricciones de excepcionalidad ordinaria", en El Cronista del Estado Social y Democrático de Derecho, monográfico Coronavirus... y otros problemas, marzo-abril 2020, pp. 88-101. Disponible en: http://www.elcronista.es/El-Cronistan\%C3\%BAmero-86-87-Coronavirus.pdf

${ }^{47}$ En especial, hay que tener en cuenta el desarrollo por el amplio apartado $4^{\circ}$ de la Orden INT/226/2020, de 15 de marzo, por la que se establecen criterios de actuación para las FCS; la Instrucción de 19 de marzo de 2020, del Ministerio de Sanidad o la Orden TMA/278/2020, de 24 de marzo, por la que se establecen ciertas condiciones a los servicios de movilidad, en orden a la protección de personas, bienes y lugares. Para el ámbito del transporte son muchas las medidas respecto de servicios profesionales, transporte público ferroviario, marítimo.

${ }^{48}$ Cabe recordar el segundo Decreto de alarma limitado a Madrid (Real Decreto 900/2020, de 9 de octubre).

${ }^{49}$ Y su acuerdo de autorización de prórroga del estado de alarma declarado por Real Decreto 926/2020. Prorrogado el estado de alarma hasta las 00:00 horas del día 9 de mayo de 2021. 
como el toque de queda bajo una prohibición general horaria de circular con más amplias excepciones ${ }^{50}$.

Sin embargo, por su naturaleza e intensidad no han generado tanta polémica constitucional en la que este estudio se centra. En cualquier caso, el Real Decreto 926/2020, de 25 de octubre de alarma también ha sido objeto de recurso de inconstitucionalidad esencialmente por suspender la libertad de circulación al adoptarse medidas reguladas en el artículo 20 LOAES $^{51}$.

$Y$ de toda relevancia es la habilitación a las restricciones de libre circulación entre territorios (arts. 6 y 9$)^{52}$. Puede considerarse que no afectan medularmente al tránsito y circulación en clave económica que esencialmente garantiza el artículo 139 CE.

Cabe señalar que con la tercera ola desde enero 2021 se dieron límites bastante fuertes materialmente. Incluso en Castilla León se amplió la franja horaria marcado por el Decreto de alarma desde las 20,00 h.-22,00 h. El Auto TS de 16 de febrero ${ }^{53}$ suspendió la decisión autonómica por ser evidentemente contraria al Decreto de alarma. Estas limitaciones que se unieron a los cierres o estrictos horarios de apertura y otras severas limitaciones de actividades económicas, de reuniones de personas o restricciones perimetrales. La conjunción de limitaciones implicaba en la práctica escasos motivos para salir a la calle. No obstante, sin perjuicio del interés del análisis de estos límites no puede equipararse al confinamiento estricto de la primera ola que, como aquí se sostiene, implicó incluso la suspensión de la libertad de circulación.

50 Especialmente ver artículos 4 y 5. Para seguir su alcance, puede seguirse ÁLVAREZ GARCÍA, V., "El comportamiento del Derecho de crisis durante la segunda ola... op. cit. pp. 30 y ss.

Recurso de inconstitucionalidad número 5342-2020, promovido por Diputados del Grupo Parlamentario de Vox en el Congreso. Disponible en: https://www.voxespana.es/wpcontent/uploads/2020/11/RECURSO-INCONSTITUCIONALIDAD.pdf

${ }^{52}$ Así, se regula su alcance, adopción por los Presidentes de las Comunidades Autónomas y excepciones (Real Decreto, art. 6.1). Adicionalmente, podrá decretarse el confinamiento perimetral "en ámbitos geográficos territoriales de carácter geográficamente inferior a la Comunidad Autónoma o a la ciudad con Estatuto de Autonomía" (art. 6.2). Esta medida, que no afecta ni a la circulación en tránsito ni al régimen de fronteras, sólo será de aplicación cuando lo determinen los Presidentes autonómicos (arts. 6.3 y 9.1).

${ }^{53}$ Disponible en:

https://www.poderjudicial.es/stfls/TRIBUNAL\%20SUPREMO/DOCUMENTOS\%20DE\%20INTE R\%C3\%89S/Auto\%20TS\%20Contencioso\%2016\%20febrero\%202021.pdf 


\section{Sí, se suspendió la libertad de circulación con el primer Decreto de alarma}

La normativa excepcional -como el Decreto de alarma- sí que "puede suspender o desplazar" la aplicación de las "leyes, normas o disposiciones con rango de ley" (STC 83/2016, de 28 de abril, FJ 10º). Así, en principio, incluso leyes orgánicas pueden dejar de aplicarse si contravienen al Decreto de alarma. Sin embargo, en ningún caso cabe la suspensión de derechos a través del estado de alarma, esta figura queda expresamente limitada a los estados de excepción o de sitio (art. 55. 1ํㅡㄹ). Sin suponer una suspensión, sí se pueden dar graves restricciones de los derechos a través de la cobertura con valor de ley del Decreto de alarma. Limitar sí, suspender no. Precisamente el Decreto de alarma dota de cobertura legal a las limitaciones que establece en razón de su valor de ley. Bajo el estado de alarma hay que aplicar canon ordinario de control a los límites a los derechos, al menos teóricamente.

Un debate importante y laberíntico es si el Decreto de alarma suspendió derechos, particularmente la libertad de circulación.

A diferencia de las posibles restricciones bajo el estado de alarma, procede recordar que, formalmente, la suspensión ${ }^{54}$ supone una desconstitucionalización que "deja sin efecto parcial o totalmente la obligatoriedad jurídica de un derecho fundamental" 55 . El régimen excepcional aplicable bajo la suspensión de un derecho podrá llevar a que los límites a los derechos puedan ser tan intensos que afecten incluso al contenido esencial del derecho suspendido. Asimismo, las garantías de legalidad quedan muy diluidas y a expensas del Derecho de excepción y sólo cabrá un canon de control limitado a la razonabilidad y en su caso a una proporcionalidad muy general.

Como he señalado supra la suspensión de la libertad de circulación no viene determinada por las restricciones que contempla el artículo 20 LOAES para el estado de excepción o de sitio, pues no pocas de las mismas incluso pueden no llegar a ser límites al derecho, o afectar al contenido esencial.

\footnotetext{
${ }^{54}$ El tema lo analizo en COTINO HUESO, L., "Los derechos fundamentales... op. cit. siguiendo a ALÁEZ, B., REQUEJO, P., DE LA QUADRA, T., en todo caso, procede seguir infra la nueva perspectiva de ESCOBAR ROCA, G., "Los derechos humanos en estados excepcionales y el concepto de suspensión de derechos fundamentales" de próxima publicación en Revista de Derecho Político, 2021, ejemplar facilitado por el autor.

${ }^{55}$ ALÁEZ CORRAL, B., "El concepto de suspensión general de los derechos fundamentales", en López Guerra, L. Espín, E. (coords.), La defensa del Estado. Actas del I Congreso de la Asociación de Constitucionalistas de España, Valencia, Tirant lo Blanch, 2004, 233-246, p. 235. Acceso completo en researchgate.net
} 
Determinar cuándo se produce la suspensión del derecho a la que alude el artículo $55 \mathrm{CE}$ se hace depender del concepto de contenido esencial del artículo 53 CE. Ya con la perspectiva de un año después, vuelvo a considerar que sí se hizo irrecognoscible la libertad de circulación haciéndola en buena medida impracticable, siguiendo los términos de la clásica STC 11/1981, de 11 de abril, FJ $8^{\circ}$ que define el contenido esencial del derecho ${ }^{56}$. En modo alguno coincido con el Defensor del Pueblo, que reduce la suspensión a que no pueda ejercerse el derecho "en absoluto" (FJ 9² ${ }^{57}$. Como he sostenido, el análisis jurídico constitucional clave es analizar el conjunto de restricciones, obstáculos, condiciones o requisitos adoptados por el Decreto de alarma para advertir si puede considerarse suspendido el derecho por cuanto se haya afectado al contenido esencial.

Kölling ${ }^{58}$ recuerda cómo en Alemania también se ha afirmado que las limitaciones han sido "la más masiva invasión colectiva de los derechos fundamentales en la historia de la República Federal".

Al parecer somos minoría quienes consideramos que se trató de una suspensión, con mayor o menor rotundidad. Cabe recordar que los catedráticos Díaz Revorio, Flores, Garrido Mayol, Ruiz Miguel, Ruiz Robledo y Vera Santos sustentaron con un dictamen un recurso ante el Tribunal Supremo frente al Decreto de alarma y sus normas de desarrollo, algunos de ellos luego como ante el Defensor del Pueblo ${ }^{59}$. Y no son pocos quienes sustentan esta tesis. Así, Aragón Reyes afirma que "Ordenar una especie de arresto domiciliario de la inmensa mayoría de los españoles [...] no es limitar el derecho, sino suspenderlo" 60 , lo cual ha ratificado meses después, señalando que para ello bastaría haber aplicado el estado de excepción ${ }^{61}$. Como ha señalado Sieira, la

\footnotetext{
${ }^{56}$ Esto es, que el derecho "sea recognoscible como pertinente al tipo descrito y sin las cuales deja de pertenecer a ese tipo y tiene que pasar a quedar comprendido en otro desnaturalizándose". De igual modo, se trata de valorar si las medidas han afectado "aquella parte del contenido del derecho que es absolutamente necesaria para que los intereses jurídicamente protegibles... resulten real, concreta y efectivamente protegidos", asimismo, que la libertad de circulación se ha "sometido a limitaciones que lo hacen impracticable, lo dificultan más allá de lo razonable o lo despojan de la necesaria protección".

${ }^{57}$ Resolución del Defensor del Pueblo de 3 de septiembre de $2020 \ldots$ cit.

${ }^{58}$ KÖLLING, M., "Las instituciones democráticas y los derechos fundamentales en tiempos de COVID-19 en Alemania", en BIGLINO CAMPOS, P. y DURÁN ALBA, J. F. (Dirs.), Los efectos horizontales de la COVID sobre el sistema constitucional, cit. p.20.

${ }^{59}$ Disponible en: https://www.dropbox.com/s/d69zsfolxw4zsac/escritoDpueblorecurso.pdf? $\mathrm{dl}=0$

${ }^{60}$ ARAGÓN REYES, M., "Hay que tomarse en serio la Constitución", El País, 10 de abril 2020.

${ }^{61}$ ARAGÓN REYES, M., "Epílogo", en BIGLINO CAMPOS, P. y DURÁN ALBA, J. F., (Dirs.) Los efectos horizontales ... op. cit. p. 13.
} 
medida del confinamiento fue un "vaciamiento" de los artículos 17 y 19 CE $^{62}$. Se trató de una auténtica "suspensión general" para Díaz Revoiro, $2020^{63}$ una prohibición general de circular. En términos similares Teruel Lozano ${ }^{64}$. 0 Amoedo, quien apunta que ello "habría obligado como requisito previo a la declaración del estado de excepción" ${ }^{65}$, se trató de "un apresurado cóctel de disciplina social con todas las herramientas disponibles del intervencionismo administrativo para lograr que la gente no salga de casa"66. De Gatta dedica una mayor atención a esta línea; sí hubo suspensión, "la regla general es que ninguna persona puede salir de los domicilios" y lo que se dio "Es una verdadera prohibición de circular que afecta a todas las personas, enfermas o no, que deben permanecer encerradas" 67 . En términos contundentes, para Ruiz Miguel hubo "una respuesta devastadora para los derechos fundamentales" al suspenderlos a través de un estado de alarma. "Se invirtió que "la regla general es la libertad y la limitación es la excepción [...] Aquí ocurre al revés, sólo se enumeran los casos en los que se puede circular" (ap. III) ${ }^{68}$. También Escobar a quien especialmente se sigue infra (VII) acaba considerando que fueron inconstitucionales por adoptarse medidas reguladas para el estado de excepción (art. 20), "es decir, se actuó en un estado de alarma como si estuviéramos en un estado de excepción" 69 .

62 SIEIRA MUCIENTES, S., "Estado de alarma", en Eunomía. Revista en Cultura de la Legalidad, núm. 19, octubre 2020 - marzo 2020, pp. 275-305, p. 296 https://doi.org/10.20318/eunomia.2020.5712

${ }_{63}$ DÍAZ REVORIO, F. J., "A vueltas con la suspensión de los derechos fundamentales", Almacén de derecho, 9 de abril 2020. Disponible en: https://almacendederecho.org/a-vueltascon-la-suspension-de-los-derechos-fundamentales

64 TERUEL LOZANO, G. M., "Control al Gobierno", El País, 8 de abril de 2020 y "Derecho de excepción y control al Gobierno: una garantía inderogable", Hay Derecho, 11 de abril de 2020. Disponible en: https://hayderecho.expansion.com/2020/04/11/derecho-excepcion-controlgobierno-garantia-inderogable/

${ }_{65}$ Ídem p. 67.

${ }^{66}$ AMOEDO-SOUTO, C. A., "Vigilar y castigar el confinamiento forzoso. Problemas de la potestad sancionadora al Servicio del estado de alarma sanitaria", en El Cronista del Estado Social y Democrático de Derecho, monográfico Coronavirus... y otros problemas, marzo-abril 2020, pp. 66-77, citas p. 67 y 68. Disponible en: http://www.elcronista.es/El-Cronistan\%C3\%BAmero-86-87-Coronavirus.pdf

${ }^{67}$ FERNÁNDEZ DE GATTA SÁNCHEZ, D., "Los problemas de las medidas jurídicas contra el coronavirus: las dudas constitucionales sobre el Estado de Alarma y los excesos normativos", Diario La Ley, núm. 9641, $2020 . \quad$ Disponible en: https://diariolaley.laleynext.es/Content/DocumentoRelacionado.aspx?params=H4sIAAAAAAAE AMtMSbF1CTEAAmMDS2NLS7Wy1KLizPw827DM9NS8kIQAhRj9kyAAAAA=WKE

${ }^{68}$ RUIZ MIGUEL, C., "Crisis del Coronavirus y crisis del Estado constitucional español", en Diario La Ley, núm. 9656, Sección Tribuna, 18 de Junio de 2020. Disponible en:

https://diariolaley.laleynext.es/Content/DocumentoRelacionado.aspx?params=H4sIAAAAAAAE AMtMSbF1CTEAAmNDQzMjE7Wy1KLizPw827DM9NS8kIQAbxAfQCAAAAA=WKE

${ }^{69}$ ESCOBAR ROCA, G., "Los derechos humanos en estados excepcionales... op. cit. 
Durán ${ }^{70}$ habla de la "sensación" de que hemos tenido suspendida la libertad de circulación. Se pregunta "¿qué mayor restricción que la padecida hasta el momento, en relación con la libertad de circulación, serían posibles para referirse en rigor a un supuesto de suspensión?". Lo mismo se cuestiona Álvarez García, qué haría falta para considerar una suspensión de la libertad de circulación; afirma que es "burdo" no considerarlo suspendido "cuando lo único que se le permite es transitar desde la cocina de su vivienda al dormitorio" ${ }^{\prime 11}$. También Sánchez Ferriz afirma la suspensión ${ }^{72}$ y Bilbao considera que se "vacía realmente de contenido el derecho y lo hace "de cuajo" ${ }^{\text {"73. }}$.

El recurso de inconstitucionalidad de Vox al primer Decreto 463/2020, de 14 de marzo de alarma se basa esencialmente en la suspensión de la libertad de circulación. Asimismo, el segundo recurso de Vox al Real Decreto 926/2020, de 25 de octubre de alarma en su apartado 62 considera "innegable" que se opera una verdadera suspensión de "de las libertades de circulación y de residencia del artículo 19 CE y de los derechos fundamentales de los arts. 17 y 25 CE". Se basan esencialmente en el artículo 20 LOAES por cuanto bajo estado de excepción se permite la prohibición de circulación de personas y vehículos en las horas y lugares que se determine y que este precepto determinaría la restricción máxima que se puede imponer a la libertad de circulación (ap. 67). Se sostiene asimismo que la técnica de la prohibición general es contraria al reconocimiento del derecho fundamental, que es la técnica que se emplea (también) en el Decreto de alarma 926/2020, que es la "técnica típica de la suspensión del derecho, con prohibición general, salvo las excepciones absolutamente indispensables". Dicha suspensión se da también para las prohibiciones de circular entre Comunidades Autónomas.

\footnotetext{
${ }^{70}$ DURÁN ALBA, J. F., "Afectaciones a la libertad de circulación... op. cit. p. 24.

71 ÁLVAREZ GARCÍA, V., "El coronavirus (COVID-19): respuestas jurídicas frente a una situación de emergencia sanitaria", El Cronista del Estado Social y Democrático de Derecho, monográfico Coronavirus... y otros problemas, marzo-abril 2020, pp. 6-21, pp. 12-13. Disponible en: http://www.elcronista.es/El-Cronista-n\%C3\%BAmero-86-87-Coronavirus.pdf

72 SÁNCHEZ FERRIZ, R., "Reflexiones constitucionales desde el confinamiento", en Actualidad Jurídica Iberoamericana, núm. 12 bis, mayo 2020, pp. 16-23, p. 21.

${ }^{73}$ BILBAO UBILLOS, J. M., "La libertad de reunión y manifestación ... op. cit. p. 6.
} 


\section{La "mayoría" considera que no hubo suspensión de la libertad de circulación}

Para Garrido López y Velasco Caballero la medida fue necesaria y proporcional -en lo que estoy de acuerdo-, pero no suspensiva, por adoptarse, con suficientes excepciones, resultar proporcional y ser compatible con lo que se hizo en países de nuestro entorno ${ }^{74}$. Por lo general sin mayor argumentación, no consideran que hubo una suspensión de derechos De La Quadra-Salcedo, Arroyo, Villaverde, Urías, Bacigalupo, Tajadura, Velasco, Leiva o Sarrión. ${ }^{75}$

Figueroa ${ }^{76}$ fundamenta en lo posible que no hubo suspensión por la existencia de excepciones y especialmente por quedar una de ellas más abierta con remisión a causas justificadas en razón de "Cualquier otra actividad de análoga naturaleza" (art. 7.1.h Decreto 463/2020, de 14 de marzo). A su juicio esto es clave porque se permite la posibilidad de ponderación. Parte de que el derecho fundamental de la libertad de circulación es un principio que no está delimitado

\footnotetext{
${ }^{74}$ GARRIDO LÓPEZ, C., "La naturaleza bifronte del estado de alarma y el dilema limitaciónsuspensión de derechos", en Teoría y realidad constitucional, núm. 46, 2020, pp. 371-402, p. 383.Sobre la no suspensión, pp. 388 y ss. VELASCO CABALLERO, F., "Medidas "individualizables" frente a medidas "generales" en la lucha contra la COVID-19: una respuesta a Javier Barnes" en Blog de Francisco Velasco, 14 de agosto, 2020. Disponible en: https://franciscovelascocaballeroblog.wordpress.com/2020/08/14/medidas-indivualizablesfrente-a-medidas-generales-en-la-lucha-contra-la-COVID-19-una-respuesta-a-javier-barnes/ ${ }^{75}$ DE LA QUADRA-SALCEDO, T., "Límite y restricción, no suspensión", El País, 8 de abril 2020; ARROYO GIL, Antonio, “¿Estado de alarma o estado de excepción?”, Agenda Pública, 12 de abril de 2020; VILLAVERDE MENÉNDEZ, I., "COVID-19: la gran prueba de estrés para los sistemas constitucionales", The conversation, 14 de mayo de 2020; URÍAS MARTÍNEZ, J., "Estado de alarma y limitación de derechos: ni excepción, ni suspensión", AlRevesyalDerecho, 99 de abril de 2020; BACIGALUPO, M., "Estado de alarma y confinamiento domiciliario: sí, es lícito", 26.3.2020, Fundación FIDE, Disponible en: https://www.fidefundacion.es/Estado-dealarma-y-confinamiento-domiciliario-si-es-licito_a1232.html.

Con cierta atención, LEIVA ESCUDERO, G., "Constitucionalidad de las restricciones a la libertad de circulación en el estado de alarma por el coronavirus COVID-19", en Diario La Ley, núm. 9642, Sección Doctrina, 28 de Mayo de 2020. Disponible en: https://diariolaley.laleynext.es/Content/DocumentoRelacionado.aspx?params=H4sIAAAAAAAE AMtMSbF1CTEAAmMDSzMjQ7Wy1KLizPw827DM9NS8kIS15JzUxCKXxJJU58Sc1LyUxCLbkK LSVADkQvFBNwAAAA==WKE SARRIÓN, ESTEVE, J., "Limitaciones a los derechos fundamentales en la declaración del estado de alarma para la gestión de la situación de crisis sanitaria ocasionada por el COVID-19", en RODRÍGUEZ AYUSO, J. F. y ATIENZA MACÍAS, E. (Coords.) Las respuestas del Derecho a las crisis de salud pública, Dykinson, 2020, pp. 15-28, (versión previa pruebas, p. 43). TAJADURA TEJADA, J. "Derecho de crisis y Constitución". Disponible en: https://elpais.com/elpais/2020/03/16/opinion/1584364474_350250.html VELASCO CABALLERO, F., "¿Que no, que ni hay suspensión de derechos, ni hace falta un estado de excepción?" en Blog de Francisco Velasco, 11 abril, 2020. Disponible en: https://franciscovelascocaballeroblog.wordpress.com/2020/04/11/que-no-que-ni-haysuspension-de-derechos-ni-hace-falta-un-estado-de-excepcion/

${ }^{76}$ GARCÍA FIGUEROA, A., "Estado de alarma... op. cit.
} 
ex ante como regla, sino que puede tener límites a posteriori (externos). La suspensión "no es una cuestión de cantidad... sino de calidad". Por el hecho de que no podamos circular, el principio de la libertad de circulación "no pierde validez". Introducir la ponderabilidad excluye que sea una suspensión. Se sigue también a Bacigalupo en esta dirección ${ }^{77}$. Y en línea similar De la Quadra no considera que hubo suspensión porque el confinamiento quedó sometido a proporcionalidad y ponderación ${ }^{78}$.

Ahí quedan las argumentaciones de dos posiciones contrapuestas. Y en esta última ciertamente no se parte de las mismas coordenadas que quien suscribe. Según sostengo, sólo es posible afectar legítimamente al contenido esencial del derecho bajo la figura constitucional de la suspensión y sólo procede la suspensión bajo el estado de excepción o sitio. Todo ello en razón de mandatos directos de la Constitución (arts. 55, 116 y 53 CE) y no tanto por lo prescrito por la LOAES, que no es el referente.

Considero que para eludir estos mandatos constitucionales habría que argumentar que sí que es posible suspender derechos fuera de estos supuestos. Como ahora se expone esto es lo que llega a afirmar especialmente Muñoz Machado. Pero lo veo insostenible.

Garrido parte de que no hubo suspensión, pero en todo caso, de forma muy sólida justifica constitucionalmente las medidas al amparo de los antecedentes constitucionales y de los principios de necesidad y proporcionalidad consustanciales al derecho de excepción ${ }^{79}$. Quien suscribe en modo alguno duda de la operatividad del principio constitucional de necesidad para situaciones como la constitucionalidad de la actuación del Rey Juan Carlos I el 23 de febrero de $1981^{80}$. Sin embargo, en aquella situación las alternativas constitucionales para actuar frente al golpe de estado eran mínimas y en modo alguno parecían eficaces frente a la actuación que realizó el monarca. Sin embargo, es mucho más cuestionable que la opción por adoptar un estado de

\footnotetext{
${ }^{77}$ BACIGALUPO, M., "Estado de alarma y confinamiento domiciliario: sí, es lícito", 26.3.2020, Fundación FIDE. Disponible en: https://www.fidefundacion.es/Estado-de-alarma-yconfinamiento-domiciliario-si-es-licito_a1232.html.

${ }^{78}$ DE LA QUADRA-SALCEDO, T., "Estado Autonómico y lucha contra la pandemia" en BIGLINO CAMPOS, P. y DURÁN ALBA, J. F., Los efectos horizontales ... op. cit. pp. 17 y ss. También, "Límite y restricción, no suspensión", El País, 8 de abril 2020

${ }^{79}$ GARRIDO LÓPEZ, C., "La naturaleza bifronte... op. cit. pp. 388, 396, 398 y ss.

80 "La posición del Rey durante la situación vivida el pasado 21 de febrero de 1981", AAVV, VII Jornadas de Derecho parlamentario. El Título Il de la Constitución. La monarquía parlamentaria, Congreso de los Diputados-Secretaría General, Madrid, 2002, pp. 601-649. Acceso en www.cotino.es.
} 
excepción no hubiera sido tan eficaz, como el estado de alarma y que no podía tomarse en un tiempo muy breve como exigía la situación. En cualquier caso, no se puede desconocer que el principio de necesidad impulsa la adopción de medidas inmediatas por el Gobierno que deben ser analizadas con deferencia constitucional. Así, cabría justificar la no adopción del estado de excepción por la convulsión del momento al inicio. Luego ya se trató de dinámica política de no corregir el rumbo que es más cuestionable.

\section{Y el más difícil todavía: sí que hubo suspensión de derechos, pero para ello basta con la legislación de salud}

Muñoz Machado se distingue en la doctrina ${ }^{81}$. No duda en afirmar que el confinamiento estricto supuso una suspensión de derechos ${ }^{82}$. Pero el estado de excepción no era la solución, pues para este autor no era preciso ni siquiera un estado de alarma: "si bien el estado de alarma no permite suspender derechos, sí lo permite la legislación sanitaria a la que el artículo 12.1 de la Ley de 1981 [LOAES] se remite" ${ }^{\prime 3}$. Cabe recordar que la LOAES en su artículo 12. $1^{\circ}$ afirma que podrán adoptarse "además de las medidas previstas en los artículos anteriores [estado de alarma, en su caso otros estados], las establecidas en las normas para la lucha contra las enfermedades infecciosas" (íd.).

Ello va unido a la tesis de no pocos administrativistas -y que en absoluto se comparte $^{84}$ - de que el artículo 3 Ley Orgánica 3/1986 permite adoptar cualquier medida restrictiva de derechos ${ }^{85}$. Es más, a ello que se une la tesis también de

${ }^{81}$ MUÑOZ MACHADO, S., "El poder y la peste de 2020", en El Cronista del Estado Social y Democrático de Derecho, núms. 90-91, 2020-2021, pp. 114-131, ver pp. 124 y ss.

${ }^{82}$ Ibídem, p. 126.

${ }^{83}$ Ibídem, p. 127.

${ }^{84}$ Supra nota 12.

${ }^{85}$ Ciertamente son legión entre administrativistas, sin que conozca un constitucionalista que mantenga las tesis de ÁLVAREZ GARCíA, J., "El comportamiento del Derecho de crisis durante la segunda ola de la pandemia", en El Cronista del Estado Social y Democrático de Derecho, núms. 90-91, 2020-2021, pp. 26-41, p. 34, GAMERO CASADO, E., "Legalidad y control de las nuevas limitaciones de derechos ante rebrotes del COVID-19", en Almacén de Derecho 27 de agosto 2020. Disponible en: https://almacendederecho.org/legalidad-y-controlde-las-nuevas-limitaciones-de-derechos-ante-rebrotes-del-COVID-19, NOGUEIRA LÓPEZ, A., "Confinar el coronavirus. Entre el viejo derecho sectorial y el derecho de excepción", El Cronista del Estado Social y Democrático de Derecho, n. $.96-87,2020$, p. 27, VELASCO CABALLERO, F., "Medidas "individualizables"... op. cit. BOIX PALOP, A., "COVID-19: La batalla jurídica contra la y los estados de alarma 'territorializados"', 8 de septiembre de 2020. Disponible en: http://www.lapaginadefinitiva.com/aboix/?p=1722, LEIVA ESCUDERO, G., "Constitucionalidad de las restricciones... op. cit. Pese a que algunos reconocen las carencias de la Ley Orgánica 3/1986 (VELASCO CABALLERO, F.). Para algunos, el artículo 3 de la Ley 
Muñoz Machado o Álvarez García ${ }^{86}$ de que para adoptar restricciones masivas al amparo de la LOMESP y la legislación sanitaria ni siquiera es necesario el control judicial de la LJCA (antes art 8.6으, ahora arts.10. $8^{\circ}$ y 11. $1^{\circ}$ i). Así pues, frente a los mandatos de la Constitución, en virtud de una remisión de la LOAES a las cuatro palabras del artículo 3 LOMESP se puede suspender derechos y sin aplicar siquiera la garantía especialmente prevista para estos casos por la propia legislación.

La fundamentación de esta tesis -que no se comparte- inicialmente es histórica. Los estados de excepción tienen que ver con el orden público e históricamente las restricciones por pandemia han sido ajenas a este ámbito, pero la LOAES que supuso un "radical cambio de criterio". La regulación LOAES "Ni mejora ni aclara la regulación precedente, sino que la empeora". A partir de ahí considera que la legislación de excepción no aporta nada respecto del artículo 11 LOAES. "Ninguna de esas medidas requeriría la declaración de estado de alarma porque la legislación sanitaria, que se pretende complementar, tiene resortes bastantes para habilitar a las autoridades a que tomen medidas como las enunciadas, o parecidas a ellas." $\mathrm{Y}$ hay que recordar al lector, que el artículo 3 LOMESP simplemente contiene la previsión de medidas "que se consideren necesarias en caso de riesgo de carácter transmisible" ${ }^{87}$.

Para Leiva, la legislación sanitaria también era suficiente para el confinamiento, pese a la "evidente la oscuridad y falta de claridad y precisión de la actual normativa sanitaria". En todo caso, reconoce que "no obstante que el estado de alarma produce ciertos efectos jurídicos muy relevantes"88. También Álvarez García señala que la restricción de movimientos podía adoptarse con la normativa ordinaria. No obstante, resulta útil su "relevancia simbólica de primer

Orgánica 3/1986 es "Un precepto legal cristalinamente claro", DOMÉNECH, G., "Comunidades autónomas, derechos fundamentales y COVID-19", Almacén de Derecho, 21 de julio 2020. Disponible en: https://almacendederecho.org/comunidades-autonomas-derechosfundamentales-y-COVID-19

${ }^{86}$ ÁLVAREZ GARCÍA, V., "La devolución competencial a las comunidades autónomas tras la recentralización operada para hacer frente a la pandemia de COVID-19", en Revista General de Derecho Administrativo, núm. 55, 2020, p. 19 recuerda su tesis de que no debía aplicarse el 8.6 LJCA, también en "El comportamiento del Derecho de crisis durante la segunda ola... op. cit. pp. 29 y 30.

${ }_{87}$ Ibídem, p. 125.

${ }^{88}$ LEIVA ESCUDERO, G., "Constitucionalidad de las restricciones a la libertad de circulación en el estado de alarma por el coronavirus COVID-19", en Diario La Ley, núm. 9642, Sección Doctrina, 28 de Mayo de 2020. Disponible en: https://diariolaley.laleynext.es/Content/DocumentoRelacionado.aspx?params=H4sIAAAAAAAE AMtMSbF1CTEAAmMDSzMjQ7Wy1KLizPw827DM9NS8kIS15JzUxCKXxJJU58Sc1LyUxCLbkK LSVADKQVFBNwAAAA $==$ WKE 
orden"89. Se trata de un factor sociológico en modo alguno desdeñable, especialmente en la primera ola de 2020 que se trataba de una situación totalmente novedosa.

\section{ESTADO DE EXCEPCIÓN Y DUDOSA ALTERACIÓN DEL ORDEN PÚBLICO}

\section{Una "mayoría" considera que no se dio el presupuesto del estado de excepción}

Cabe especialmente acudir a Garrido López sobre la idoneidad de recurrir al Derecho excepcional para dar respuesta a la pandemia ${ }^{90}$. A mi juicio ello es así mientras no se mejore la muy deficiente legislación sanitaria. $Y$ me permito añadir que especialmente queda indicado dada la insuficiente regulación sanitaria. Ya en particular, Garrido sostiene que procedía adoptar el estado de alarma, pese a las claras insuficiencias de su regulación en la LOAES, que hubieron de ser superadas mediante una interpretación constitucionalmente conforme con la irreductible naturaleza bifronte del estado de alarma. El principio de necesidad ínsito en la propia regulación de los estados excepcionales permite superar la "rigidez e insuficiencia" de las limitadas medidas de la LOAES y adoptar otras ${ }^{91}$. El sustento de esta tesis es loable y en cualquier caso hay que seguirlo para superar las deficiencias $y$ encorsetamientos de la LOAES. Y también en la línea expuesta sobre la no existencia de un bloque de constitucionalidad. Sin embargo, pese a lo fundamentada que es esta tesis a mi juicio es difícil eludir el expreso mandato constitucional de la necesidad del estado de excepción para poder suspender la libertad de circulación.

La cuestión se complica al analizar si se dio alteración del orden público, que es el presupuesto del estado de excepción de la LOAES. No pocos autores, para algunos la "mayoría", están a favor de la adecuada adopción del primer Decreto de alarma. Y no sólo porque no hubo suspensión, sino porque no se

\footnotetext{
${ }^{89}$ ÁLVAREZ GARCÍA, V., "El coronavirus (COVID-19): respuestas jurídicas... op. cit. pp. 17-18.

${ }^{90}$ GARRIDO LÓPEZ, C., "La naturaleza bifronte... op. cit. in toto.

${ }^{91}$ GARRIDO LÓPEZ, C., "La naturaleza bifronte... op. cit. en general, referencia de p. 400.
} 
dio el presupuesto de la grave alteración del orden público que exige el artículo 13. $1^{\circ}$ LOAES para la adopción del estado de excepción ${ }^{92}$.

Esta posición la suscriben García Figueroa, Presno Linera, Martínez Alarcón, Castellà Andreu, López Garrido, Cruz Villalón, Rallo Lombarte o Carrillo ${ }^{93}$. Asimismo, para Cruz las medidas no cabían "con arreglo a las categorías constitucionales disponibles"94.

En la primera resolución sobre el tema, el TC parece apuntarse esta tesis: la LOAES quedó superada y no se dio el presupuesto de alteración del orden público. Así, el ATC 40/2020, de 30 de abril, afirma que la pandemia revistió por sus efectos "dimensiones desconocidas hasta la fecha. Desconocidas y, desde luego, imprevisibles cuando el legislador articuló la declaración de los estados excepcionales en el año 1981" (FJ 4º). Asimismo, "Y no se trata aquí de garantizar el orden público o de asegurar la no alteración del orden público. Tampoco la declaración del estado de alarma se ha basado en la preservación del orden público, sino en la garantía del derecho a la integridad física y la salud de las personas." (FJ $\left.4^{\circ}\right)$.

Para el Defensor del Pueblo "los estados de excepción y sitio no eran posibles", "No puede reprocharse que, excluidos los estados de excepción y sitio por no concurrir sus presupuestos, fuera elegido el estado de alarma". Con rotundidad afirma que el estado de excepción "no se sostiene: ni había un

92 "Cuando el libre ejercicio de los derechos y libertades de los ciudadanos, el normal funcionamiento de las instituciones democráticas, el de los servicios públicos esenciales para la comunidad, o cualquier otro aspecto del orden público, resulten tan gravemente alterados que el ejercicio de las potestades ordinarias fuera insuficiente para restablecerlo y mantenerlo, el Gobierno, de acuerdo con el apartado tres del artículo ciento dieciséis de la Constitución, podrá solicitar del Congreso de los Diputados autorización para declarar el estado de excepción.

${ }^{93}$ GARCÍ́A FIGUEROA, A., "Estado de alarma... op. cit. PRESNO LINERA, M. A., "Estado de alarma y sociedad del riesgo global", en RODRÍGUEZ AYUSO, J. F. y ATIENZA MACÍAS, E. (Coords.) Las respuestas del Derecho a las crisis de salud pública, Dykinson, Madrid, 2020, p. 24. MARTÍNEZ ALARCÓN, M. L., "¿Es el estado de alarma en España un estado de excepción encubierto?", The conversation, 30 de marzo de 2020. Disponible en: https://theconversation.com/es-el-estado-de-alarma-en-espana-un-estado-de-excepcionencubierto-135358. CASTELLÀ ANDREU, J. M., "Incidencia de la COVID-19 sobre la democracia constitucional: reflexiones desde España", Letras Libres, 15 de abril 2020, https://www.letraslibres.com/espana-mexico/politica/incidencia-la-COVID-19-sobre-la-

democracia-constitucional-reflexiones-desde-espana. LÓPEZ GARRIDO, D., "Un estado de excepción sería inconstitucional", Eldiario.es, 11 de abril de 2020 https://www.eldiario.es/opinion/tribuna-abierta/excepcion-inconstitucional_129_2262738.html.

RALLO LOMBARTE, A., "Estado de alarma versus estado de excepción: una polémica estéril", Eldiario.es, 27 de abril de 2020. CARRILLO, M., "Los derechos en tiempo de pandemia", Al revés $y$ al derecho, 17 de mayo de 2020. Disponible en: http://blogs.infolibre.es/alrevesyalderecho/?p=5800 CRUZ VILLALÓN, P., "La Constitución bajo el estado de alarma", El País, 17 de abril 2020.

94 Ibídem. 
problema de orden público ni procedía la suspensión de derechos fundamentales". De mayor interés a mi juicio es que se apunta de modo interesante que ante la mínima duda sobre su pertinencia no había que optar por la adopción del estado de excepción, que hubiera sido más invasivo. (FJ $\left.9^{\circ}\right)^{95}$. Se trata de un interesante argumento. Pero es difícil sostener que por adoptarse el estado de excepción este hubiera venido acompañado de otras medidas más restrictivas, que de hecho no se han adoptado en ningún momento. Y al mismo tiempo, como desde el inicio señaló Díaz Revoiro frente a este argumento ${ }^{96}$, el estado de excepción precisamente es más garantista, tiene mayor control y mitiga notoriamente el "protagonismo" que el Gobierno tiene en el estado de alarma.

\section{Y otra "mayoría" entiende que sí que procedía el estado de excepción}

Del lado contrario, no son pocos los autores que sí que consideran que se dio el presupuesto para declarar el estado de excepción. En general cabe remitir a los mencionados autores que afirman que sí se dio la suspensión de la libertad de circulación. En general, sobre la base del propio texto del artículo 20 LOAES, se maneja un concepto amplio de orden público. Así, Sánchez Ferriz afirma que sí que se afectó el orden público, como "mantenimiento del orden constitucional", por lo que procedía la declaración del estado de excepción, lo cual, además, hubiera llevado a "la necesidad de pactar, de hablar, de oír otras partes" 97 . Sieira señala que "la crisis desbordaba el marco de una simple crisis sanitaria y tenía connotaciones de quiebra grave del orden público" 98 no de la quietud o tranquilidad de los ciudadanos, sino de la posibilidad de ejercer sus derechos. $Y$ en la semana del Decreto de alarma se podía haber solicitado autorización del estado de excepción.

En la línea de la procedencia del estado de excepción -con mayor o menor argumentación- cabría situar a Aragón Reyes, Martínez Alarcón, Nogueira, Amoedo, Castellà o Díaz Revorio, para quien el desbordamiento del sistema sanitario bien cabe en este presupuesto ${ }^{99}$. También el TSJ Aragón afirmó que

\footnotetext{
${ }_{95}^{95}$ Resolución del Defensor del Pueblo de 3 de septiembre de $2020 \ldots$ op. cit.

${ }^{96}$ DÍAZ REVORIO, F. J., "A vueltas con la suspensión... op. cit.

${ }^{97}$ SÁNCHEZ FERRIZ, R., "Reflexiones constitucionales desde el confinamiento", op. cit., pp. 20 y 22.

${ }^{98}$ SIEIRA MUCIENTES, S., "Estado de alarma", op. cit. p. 296.

99 ARAGÓN REYES, M., "Hay que tomarse en serio la Constitución", El País, 10 de abril 2020. Ver también ARAGÓN REYES, M., "Editorial. COVID-19: aproximación constitucional a una
} 
"la herramienta más adecuada" era el estado de excepción ${ }^{100}$. Cabe señalar que la diferencia entre suspensión y restricción en algunos TSJ erróneamente se ha llevado al contexto de si la LOMESP era suficiente para las restricciones masivas de derechos o era necesario el estado de alarma para suspender los derechos $^{101}$.

Sánchez Ferriz, entiende que la "comodidad" y las prisas llevaron a adoptar el estado de alarma y no el de excepción, que a su juicio era el que correspondía $^{102}$. En esta línea Siera ${ }^{103}$ echa de menos una vía de urgencia para el derecho de excepción que sí hubo en las Constituciones de 1869 y $1931^{104}$. Se aboga por que el Gobierno pueda suspender garantías en situaciones graves bajo su responsabilidad, con convalidación inmediata a posteriori del Congreso.

Ruiz Miguel apunta originalmente "La inexplorada posibilidad de la declaración simultánea de diversos estados de emergencia" ${ }^{105}$. Parte de que el Decreto de alarma implicaba la suspensión de derechos y hubiera procedido el estado de excepción, por lo que la aprobación del Decreto de alarma lo fue "hurtando el procedimiento y las garantías propias del estado de excepción. Ello se hubiera

crisis", Revista General de Derecho Constitucional, núm. 32, 2020. NOGUEIRA LÓPEZ, A., "Confinar el coronavirus. Entre el viejo derecho sectorial y el derecho de excepción", El Cronista del Estado Social y Democrático de Derecho, núms. 86-87, 2020, p. 27. AMOEDOSOUTO, C., "Vigilar y castigar el confinamiento forzoso. Problemas de la potestad sancionadora al servicio del estado de alarma sanitaria", El Cronista del Estado Social y Democrático de Derecho, n. 86- 87, 2020, p. 66. DIÁZ REVORIO, F. J., "A vueltas con la suspensión de los derechos fundamentales", Almacén de derecho, 9 de abril de 2020. MARTÍNEZ ALARCON, M. L., "¿Es el estado de alarma en España un estado de excepción encubierto?", The conversation, 30 de marzo de 2020 y PRESNO LINERA, M. A., "Estado de alarma y sociedad del riesgo global", en RODRíGUEZ AYUSO, J. F., y ATIENZA MACÍAS, E. (Dirs.), Las respuestas del Derecho a las crisis de salud pública, Dykinson, Madrid, 2020, p. 24.

100 "[c]abe plantearse de manera más que razonable que una situación de crisis sanitaria como la que sufrimos en estos momentos puede implicar de facto una tan grave alteración del libre ejercicio de los derechos y libertades de los ciudadanos, o del normal funcionamiento de las instituciones, que haga razonable pensar que la herramienta más adecuada para el restablecimiento de tal normalidad de ejercicio pueda ser el estado de excepción [...]". (STSJ AR 224/2020, 28 de abril, FJ 3.ํ).

101 Así, el TSJ Castilla León, auto 273/2929 de 25 de octubre, no admitió el toque de queda nocturno porque sería una "suspensión" de derechos a acometer por Decreto de Alarma (FJ $\left.4^{\circ}\right)$. Algún TSJ también oscila en estos conceptos. Disponible en: https://t.co/XG8gavYYax?amp=1

${ }_{102}$ SÁNCHEZ FERRIZ, R., "Reflexiones constitucionales desde el confinamiento", op. cit. p. 19. 103 SIEIRA MUCIENTES, S., "Estado de alarma", op. cit. 302.

104 SIEIRA MUCIENTES, S., "Los estados excepcionales", op. cit.

105 RUIZ MIGUEL, C., "Crisis del Coronavirus y crisis del Estado constitucional español", en Diario La Ley, núm. 9656, Sección Tribuna, 18 de junio de 2020. Disponible en:

https://diariolaley.laleynext.es/Content/DocumentoRelacionado.aspx?params=H4sIAAAAAAAE AMtMSbF1CTEAAmNDQzMjE7Wy1KLizPw827DM9NS8kIQAbxAfQCAAAAA=WKE 
resuelto con la declaración conjunta de alarma y excepción, "o, al menos, intentar que ambos puedan tener vigencia simultánea", que hubiera implicado la participación del Congreso.

Ciertamente se trata de posibilidades especialmente pro futuro casi impensables para el momento en el que se dio la urgencia. Por mi parte, inicialmente consideré y es posible sostener que no hubo alteración del orden público. Sin embargo, creo que lo importante es que la alteración del orden público para declarar el estado de excepción no es una exigencia de naturaleza constitucional, no deriva del artículo 55 o 116 CE. Es una exigencia de la LOAES que ha fijado el presupuesto para declarar el estado de excepción siguiendo el mandato regulatorio del artículo 116 CE. Sin embargo, no conforma bloque de constitucionalidad. Mientras que, por el contrario, sí que es imposición constitucional clara que para suspender la libertad de circulación debe acudirse al estado de excepción por exigencia. Es decir, la necesidad de cumplir con la Constitución permitía una interpretación de la LOAES para la adopción del estado de excepción. En cualquier caso, como se ha adelantado, la opción inicial por el Decreto de alarma se puede justificar constitucionalmente sobre la base de la necesidad.

\section{OTRA POSIBLE VÍA DE SOLUCIÓN APORTADA POR ESCOBAR A UNA SITUACIÓN LABERÍNTICA}

Sin duda se trata de una situación laberíntica, Figueroa afirma un "dilema sin solución"106. Y quizá el mejor camino para la resolución del mismo lo pone recientemente Escobar ${ }^{107}$. No en vano, demuestra que no son tan diversas las categorías de la restricción y de la suspensión de derechos en perspectiva internacional y comparada, y especialmente desde las garantías de los derechos fundamentales.

Así, examina la doctrina española, que en términos generales y como aquí se ha seguido, implica que bajo la suspensión de derechos no se elude el control de proporcionalidad, si bien no se garantiza el mínimo del contenido esencial (Requejo Rodríguez, Aláez Corral, De la Quadra, Garrido López). Sin embargo,

\footnotetext{
${ }^{106}$ GARCíA FIGUEROA, A., "Estado de alarma... op. cit.

107 ESCOBAR ROCA, G., "Los derechos humanos en estados excepcionales y el concepto de suspensión de derechos fundamentales" de próxima publicación en Revista de Derecho Político, 2021, ejemplar facilitado por el autor.
} 
estas aportaciones nacionales le dejan "insatisfecho". De ahí que para construir un concepto de suspensión se vuelque en una lectura internacional. Ello le lleva a constatar que también en el caso de la suspensión se exigen los principios de legalidad, proporcionalidad e incluso de la preservación de un mínimo. La suspensión de derechos en el ámbito del $\mathrm{CEDH}$, también analizada por Roca ${ }^{108}$, le lleva a concluir que el TEDH "ha ido progresivamente acercándose a un control estricto, deferente pero no demasiado lejano al propio de las situaciones de normalidad". Y ello se "reitera en otros organismos internacionales, en una sorprendente coincidencia, reveladora de un diálogo

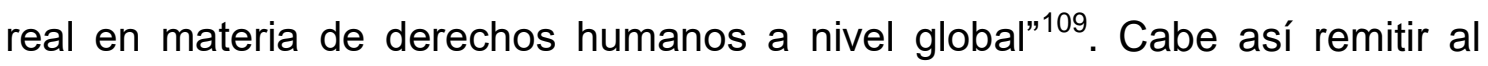
exhaustivo análisis de la doctrina del TEDH que realiza Escobar, así como al amplio estudio internacional que él mismo ha liderado de la mano de la Red $\mathrm{FIO}^{110}$. Entre otros se ha de tener en cuenta la compilación de la Comisión de Venecia de opiniones e informes sobre estados de emergencia, de 16 de abril de $2020^{111}$ que también analiza Castellà ${ }^{112}$ y otro soft law europeo. Todo ello siempre en el sentido de reconducir la suspensión de derechos al principio de proporcionalidad. Expone Escobar ${ }^{113}$ con detalle cómo el Comité de Derechos Humanos mediante la Observación General n² 29, de 24 de julio de 2001 asume la doctrina de un control "aún más estricto". Así las cosas, suspensión viene a ser equivalente a restricción con previsión legal contenido mínimo y proporcionalidad. El análisis internacional le lleva a demostrar que en los tres sistemas de derechos humanos (universal, europeo e interamericano), no hay diferencia en la práctica entre declarar o no declarar el estado excepcional.

Así pues concluye "no existe diferencia sustancial entre restricción y suspensión de derechos": los derechos "suspendidos" formalmente continúan

\footnotetext{
${ }^{108}$ ROCA FERNÁNDEZ, M. J., "La suspensión del Convenio Europeo de Derechos Humanos desde el Derecho español: Procedimiento y Control", Revista española de derecho europeo, núm. 72, 2019, pp. 43-71.

109 Ibídem.

110 ESCOBAR ROCA, G. (Coord.), Informe de la Federación Iberoamericana del Ombudsman sobre derechos humanos, estados excepcionales y COVID-19, Red FIO, Trama, Madrid, 2021. Acceso en www.portalfio.org

111 En castellano, con presentación de CASTELLÀ ANDREU, J. M., "Compilación de la Comisión de Venecia de estudios e informes sobre el estado de alarma", Revista General de Derecho Constitucional, n. 32 2020, pp. 1-7,

${ }_{112}$ CASTELLÀ ANDREU, J. M., "La Comisión de Venecia y los estados de emergencia: la necesaria preservación del estado de derecho y la democracia constitucional durante la crisis de la COVID-19" en BIGLINO CAMPOS, P. y DURÁN ALBA, J. F., Los efectos horizontales de la COVID ...cit. p. 4. Disponible en: https://www.fundacionmgimenezabad.es/es/los-efectoshorizontales-de-la-COVID-19-sobre-el-sistema-constitucional-estudios-sobre-la-primera ${ }^{113}$ Ibídem.
} 
vigentes, si bien se da una mayor discrecionalidad estatal tanto para la definición y consecución de un objetivo legítimo como para restringir determinados derechos; determinados contenidos nunca pueden ser afectados y en todo caso, debe analizarse siempre la proporcionalidad entre las medidas restrictivas de derechos y el objetivo pretendido con ellas. $Y$ pese al debilitamiento formal no se pierden en ningún caso las garantías judiciales. Por ello no le extraña que la Carta de derechos fundamentales de la UE prescinda del concepto de suspensión de derechos ${ }^{114}$.

A mi juicio debe interpretarse la noción de "suspensión" del artículo 55 CE de conformidad con el artículo 10. 2ํㅡ CE según estos presupuestos internacionales. Ello puede llevar a difuminar la distinción entre la restricción de derechos y la suspensión. Y, por esta vía, se podría relativizar la importancia del mandato constitucional de suspender derechos a través del estado de excepción: lo realmente importante son las garantías efectivas de los límites a los derechos. El debate que se ha dado pasaría a ser en buena medida estéril. Que sea cual sea la figura jurídica que se adopte, deben darse los presupuestos consabidos de legalidad y predeterminación, razonabilidad y necesidad y proporcionalidad al tiempo de la legitimidad democrática.

Esta argumentación más internacional unida a las experiencias comparadas bien podría apoyar la decisión del TC al respecto. En todo caso, lo más importante será que el cumplimiento real de estas garantías guíe un nuevo Derecho de excepción que dé una mucha mejor respuesta a las situaciones de emergencia y en especial de emergencia sanitaria.

VIII. PARA CONCLUIR: LA INEXISTENCIA DE UN BLOQUE DE CONSTITUCIONALIDAD Y LA POSIBLE DECISIÓN DEL TRIBUNAL CONSTITUCIONAL

Por lo aquí expuesto, el confinamiento estricto supuso la suspensión de la libertad de circulación porque afectó a su contenido esencial. Pero no se trató de una suspensión por adoptarse las restricciones de la libertad de circulación de la LOAES para el estado de excepción (art. 20 LOAES). Por mandato constitucional expreso la suspensión de la libertad de circulación sólo se puede hacer a través del estado de excepción o de sitio. No se daban los

114 Ibídem. 
presupuestos legales (de la LOAES) para adoptar el estado de excepción por falta de alteración del orden público. Pero esto no es una exigencia constitucional.

La relación entre la Constitución y la LOAES no implica un bloque de constitucionalidad, esto es, un parámetro normativo para contrastar la constitucionalidad de las normas como sucede en el caso autonómico ${ }^{115}$. Velasco también niega que la LOAES integre el bloque de constitucionalidad y añade que "Es discutible que la LOEAES actúe como parámetro para el control de constitucionalidad, al menos directamente", siendo que el TC ha sido reacio a integrar a las leyes entre los cánones de constitucionalidad más allá del art. 28. 1 LOTC $^{116}$.

La vulneración de la LOAES puede implicar en supuestos concretos una vulneración de la Constitución y de los derechos fundamentales, en ocasiones puede suponer una vulneración sustantiva de la reserva de ley orgánica del artículo 116 CE y en ocasiones supondrá (sólo) una vulneración de la legalidad. Ciertamente se trata de una relación de fuentes compleja, por cuanto las normas con valor de ley del estado de excepción desplazan al Derecho ordinario. Los decretos de alarma deben ajustarse al marco de la LOAES para cumplir la concreta reserva de ley orgánica del artículo 116 CE. Según afirma Velasco, "entre ambos textos corre una reserva de procedimiento" y el deber de respetar la estructura jurídica general de los estados excepcionales, que está reservada a la ley orgánica" ${ }^{\# 17}$. Políticamente la vulneración de la legalidad ordinaria generará las responsabilidades políticas que corresponda. Jurídicamente las consecuencias de la vulneración de la legalidad ordinaria habrá que valorarlas en cada caso concreto, si bien puede anunciarse que no necesariamente implicarán una nulidad radical.

\footnotetext{
${ }^{115}$ Cabe recordar al respecto reiterada jurisprudencia constitucional y el artículo 28.1 LOTC: "Para apreciar la conformidad o disconformidad con la Constitución de una Ley, disposición o acto con fuerza de Ley del Estado o de las Comunidades Autónomas, el Tribunal considerará, además de los preceptos constitucionales, las Leyes que, dentro del marco constitucional, se hubieran dictado para delimitar las competencias del Estado y las diferentes Comunidades Autónomas o para regular o armonizar el ejercicio de las competencias de estas". Entre otras muchas STC 128/2016, de 7 de julio y, por todos, RUBIO LLORENTE, F., "El bloque de constitucionalidad", Revista española de derecho constitucional, núm. 27, 1989, pp. 9-38.

${ }^{116}$ VELASCO CABALLERO, F., "¿Es la Ley orgánica 4/1981, de los estados de alarma, excepción y sitio, parámetro de validez de los Reales Decretos de alarma?", en Blog de Francisco Velasco, 3 junio de 2020. Disponible en: https://franciscovelascocaballeroblog.wordpress.com/2020/06/03/es-la-ley-organica-4-1981-delos-estados-de-alarma-excepcion-y-sitio-parametro-de-validez-de-los-reales-decretos-dealarma/

${ }^{117}$ Ibídem.
} 
Los dos recursos de inconstitucionalidad a los dos decretos de alarma presentados por Vox afirman expresamente la existencia de tal "bloque de constitucionalidad" de alarma ${ }^{118}$ y en buena medida fundamentan en ello la pretendida inconstitucionalidad. Se afirma que: "la regulación establecida por la LO 4/1981, norma que integra el bloque de la constitucionalidad a los efectos del artículo 28.1 LOTC, sirviendo por ello de parámetro de la constitucionalidad de los RD aquí impugnados”.

En ocasiones la protección constitucional de los derechos fundamentales no coincide con la protección legal de los mismos. Pensemos por ejemplo en la protección constitucional del domicilio y la que brinda la LECRIM sobre acceso policial a locales comerciales o administraciones. Hay que estar a cada caso a las consecuencias concretas. Como se ha expuesto, la LOAES no predetermina el concepto constitucional de suspensión del artículo 55 CE. Al mismo tiempo, la adopción de un estado de excepción determinado sin los presupuestos legales por sí sola no constituye un vicio de nulidad plena si no va acompañada de una lesión de derechos fundamentales o de mandatos constitucionales concretos. En términos administrativos no aplicables, no hay que considerar que se dictaría "prescindiendo total y absolutamente del procedimiento legalmente establecido" (art. 47. $1^{\circ}$ e) Ley 39/2015) y habría que centrar más la atención en el contenido material de las restricciones de derechos fundamentales.

En términos menos jurídicos y como ya se expuso, quien suscribe entiende la situación que sobrevino a la que había dar respuesta y no se contaba con precedentes. Por el contenido material el confinamiento estricto de la primera ola fue necesario, adecuado y proporcionado además de contar inicialmente con un consenso político cercano al $90 \%$.

En todo caso, será interesante ver cómo justificará jurídicamente el TC -como probablemente hará- la constitucionalidad del primer Decreto de alarma, especialmente respecto de que supuso una suspensión porque se afectó el contenido esencial de la libertad de circulación y que para ello sólo podía adoptarse con el estado de excepción.

Aunque siempre es arriesgado y sin duda innecesario e incluso frívolo, me atrevo a vaticinar que el TC pasado un tiempo en el que esta discusión casi ni

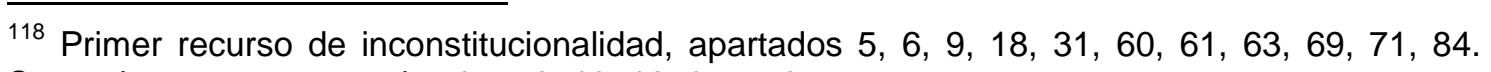
Segundo recurso, apartados $3,5,6,18,19,67$ y 79. 
se recuerde, tendrá no pocos resortes y apoyos doctrinales para dar por buenos los decretos de alarma impugnados. Se debe partir de cierta deferencia a la discrecionalidad del Gobierno a la hora de adoptar situaciones excepcionales, más en un marco jurídico incierto por falta de precedentes importantes y todo en el contexto de incertidumbre generalizada. Posiblemente se afirmará que no se suspendió el derecho, se describirán decisiones similares en otros países, se podrá acoger a un nuevo concepto de suspensión -como el sostenido por Escobar- que lleve a afirmar que se cumplieron los estándares internacionales y constitucionales de necesidad y proporcionalidad. Asimismo, muy posiblemente apoyará su decisión en que no se dio el presupuesto de alteración del orden público. Dada la expresa alusión del bloque de constitucionalidad en los recursos de inconstitucionalidad, posiblemente negará su existencia en el ámbito de excepción. No sé si el TC despejará dudas sobre la difícil relación entre la Constitución, la LOAES, las normas con valor de ley de excepción (Decreto de alarma) y otras leyes orgánicas y ordinarias.

Lo ciertamente deseable es que cuando se decida la cuestión el TC siente las bases de un mejor Derecho de excepción futuro. $Y$, sobre todo, lo más deseable es que no pase tiempo hasta que el legislador haya mejorado la deficiente legislación de excepción y, especialmente, la ordinaria para afrontar estas situaciones excepcionales. 